\title{
Assessment of Genetic Aspects of Non-alcoholic Fatty Liver
} and Premature Cardiovascular Events

\author{
Sara Saki ${ }^{1, *}$, Nader Saki ${ }^{2}$, Hossein Poustchi $^{3}$, Reza Malekzadeh ${ }^{3}$
}

1. Tehran University of Medical Sciences, Tehran, Iran

2. Hoveizeh Cohort Study, Ahvaz Jundishapur University of Medical Sciences, Ahvaz, Iran

3. Digestive Disease Research Institute, Tehran University of Medical Sciences, Tehran, Iran

\footnotetext{
* Corresponding Author: Sara Saki, MD Digestive Disease Research Institute, Shariati Hospital,Tehran, Iran Tel: + 989125148365 Fax: + 982182415000 Email: Ssaki_ir@yahoo.com
}

Received: 30 Oct. 2019 Accepted: 19 Mar. 2019

\begin{abstract}
Recent evidence has demonstrated a strong interplay and multifaceted relationship between non-alcoholic fatty liver disease (NAFLD) and cardiovascular disease (CVD). CVD is the major cause of death in patients with NAFLD. NAFLD also has strong associations with diabetes and metabolic syndrome. In this comprehensive review, we aimed to overview the primary environmental and genetic risk factors of NAFLD, and CVD and also focus on the genetic aspects of these two disorders.
\end{abstract}

NAFLD and CVD are both heterogeneous diseases with common genetic and molecular pathways. We have searched for the latest published articles regarding this matter and tried to provide an overview of recent insights into the genetic aspects of NAFLD and CVD.

The common genetic and molecular pathways involved in NAFLD and CVD are insulin resistance (IR), subclinical inflammation, oxidative stress, and atherogenic dyslipidemia. According to an investigation, the exact associations between genomic characteristics of NAFLD and CVD and casual relationships are not fully determined. Different gene polymorphisms have been identified as the genetic components of the NAFLDCVD association. Some of the most documented ones of these gene polymorphisms are patatin-like phospholipase domain-containing protein 3 (PNPLA3), transmembrane 6 superfamily member 2 (TM6SF2), hydroxysteroid 17-beta dehydrogenase 13 (HSD17B13), adiponectin-encoding gene (ADIPOQ), apolipoprotein C3 (APOC3), peroxisome proliferator-activated receptors (PPAR), leptin receptor (LEPR), sterol regulatory element-binding proteins (SREBP), tumor necrosis factor-alpha (TNF- $\alpha$ ), microsomal triglyceride transfer protein (MTTP), manganese superoxide dismutase (MnSOD), membrane-bound O-acyltransferase domain-containing 7 (MBOAT7), and mutation in DYRK1B that substitutes cysteine for arginine at position 102 in kinase-like domain.

Further cohort studies with a significant sample size using advanced genomic assessments and next-generation sequencing techniques are needed to shed more light on genetic associations between NAFLD and CVD.

\section{KEYWORDS:}

Non-alcoholic fatty liver disease, Cardiovascular disease, Gene polymorphism, Genetic aspect

\section{Please cite this paper as:}

Saki S, Saki N, Poustchi H, Malekzadeh R. Assessment of Genetic Aspects of Non-alcoholic Fatty Liver and Premature Cardiovascular Events. Middle East J Dig Dis 2020;12:65-88. doi: 10.34172/mejdd.2020.166.

\section{INTRODUCTION}

Non-alcoholic fatty liver disease (NAFLD) is a chronic liver disease accompanied by insulin resistance (IR) and metabolic syndrome (MetS). ${ }^{1,2}$ NAFLD has a wide spectrum from simple steatosis to steatohepatitis and progression to cirrhosis. ${ }^{3}$ During the last decade, strong evidence has 
demonstrated a significant link between NAFLD and cardiovascular diseases (CVDs), ranging from coronary artery disease (CAD) to subclinical carotid atherosclerosis. To predict morbidity and mortality of NAFLD, long term studies with close follow-up assessments on the treatment of risk factors for NAFLD and cardiovascular (CV) risk classification is necessary. NAFLD has strong associations with diabetes and MetS and is associated with increased risk of CVDs, independent of other traditional metabolic risk factors such as hypertension, diabetes, dyslipidemia, and obesity. However, the exact causal relationship between NAFLD and CVD factors remains uncertain. ${ }^{1,4-7}$ Considering the ever-increasing incidence of NAFLD worldwide as well as the pandemic-level rise of obesity and other metabolic disorders in one hand and the association of NAFLD with a higher risk of CVDs in other hand, the importance of appropriate management of NAFLD to reduce the incidence and morbidities and mortalities of associated CVDs is highlighted. ${ }^{8,9}$

The incidence rates of CVD are higher in patients with NAFLD, but the leading cause of mortality in these patients is CVDs. Because the prevalence of NAFLD is high among patients with metabolic risk factors for CVD, including type 2 diabetes mellitus (T2DM), obesity, and dyslipidemia, aggressive modification of CVD risk factors could potentially reduce cardiovascular and liver-related morbidity in patients with NAFLD. Although the genomic characteristics of NAFLD and CVD have been significantly investigated, the exact associations and causal relationship of these two disorders have not been fully determined. Different gene polymorphisms have been identified as the genetic association of NAFLD and CVD. Some of the well documented and validated of these gene polymorphisms are patatinlike phospholipase domain-containing protein 3 (PNPLA3), transmembrane 6 superfamily member 2 (TM6SF2), hydroxysteroid 17-beta dehydrogenase 13 (HSD17B13), adiponectin-encoding gene (ADIPOQ), apolipoprotein $\mathrm{C} 3$ (APOC3), peroxisome proliferatoractivated receptors (PPAR), leptin receptor (LEPR), sterol regulatory element-binding proteins (SREBP), tumor necrosis factor-alpha (TNF- $\alpha)$, microsomal triglyceride transfer protein (MTTP), manganese superoxide dismutase (MnSOD), and membrane-bound O-acyltransferase domain-containing 7 (MBOAT7). In this comprehensive review, we aimed to overview and summarize the current knowledge of the genetic associations between NAFLD and CVD, and also to discuss possible clinical strategies for $\mathrm{CV}$ risk assessment in patients with NAFLD.

\section{Epidemiology of NAFLD and Cardiovascular} Events

According to the World Health Organization (WHO), CVDs are the leading cause of death worldwide, responsible for approximately 18 million deaths per year. CVD represents a spectrum of disorders ranging from coronary heart disease, cerebrovascular disease, and rheumatic heart disease. ${ }^{10}$ About $80 \%$ of CVD related mortalities are caused by heart attacks and strokes, and $75 \%$ of these deaths occur prematurely in individuals aged less than 70 years. ${ }^{8}$ The worldwide prevalence of metabolic diseases such as T2DM, obesity, and NAFLD, which are the common risk factors for CVD, has dramatically increased worldwide during the last decades. NAFLD is the most common cause of liver disease worldwide, with $75 \%$ of all chronic liver diseases (CLDs). CVD is currently the first cause of mortality in patients with NAFLD, indicating a significant association between CVD and NAFLD. ${ }^{11}$ Different molecular mechanisms and genetic features have been attributed to the CVDNAFLD association, including oxidative stress, adipokines, lipotoxicity, endoplasmic reticulum stress, low-grade systemic inflammation, and microbiota dysbiosis. These factors are, in turn, influenced by different genetic and epigenetic variations. Despite the strong evidence that recently published on the NAFLD-CVDs associations, the causal relationship, and the exact mechanisms of NAFLD contributions to CVDs are not fully understood.

Individuals with elevated CVD risk have high blood pressure and high glucose levels. They can also be overweight and obese, thus more susceptible to liver disorders. ${ }^{12,13}$ Measurements and monitoring of these parameters are convenient in primary care facilities. Identifying individuals with the highest CVD 
risks and administering appropriate treatments can effectively prevent premature deaths among these individuals. In some individuals, NAFLD can progress to advanced fibrosis, cirrhosis, and hepatocellular carcinoma. NAFLD is often associated with IR and is strongly associated with T2DM and obesity. Patients with NAFLD show a higher risk of progression to non-alcoholic steatohepatitis (NASH) and cirrhosis. They are also at higher risk of CVDs, including coronary heart disease and stroke. ${ }^{14}$ Recent evidence has revealed that NAFLD, as a risk factor for CVD, is independent of traditional cardiovascular risk factors and MetS. ${ }^{2}$

NAFLD is traditionally diagnosed using either histological or imaging assessments. Abnormal liver enzymes have been successfully used as biochemical surrogates of NAFLD in different studies. ${ }^{15}$ Different prospective cohort studies have shown that elevated alanine aminotransferase (ALT) could be a biomarker of increased CVD risk in patients with NAFLD so that such patients identified based on elevated ALT had higher CVD related mortalities. Similarly, several studies have demonstrated an association between elevated ALT and increased CVD-related mortalities. ${ }^{16,17}$ Another biomarker for NAFLD is gamma-glutamyl transferase (GGT). Elevated GGT has been reported as a surrogate of CVD in patients with NAFLD. ${ }^{18}$ Imaging of the liver could be a reliable approach for the definitive diagnosis of NAFLD. Three extensive cohort studies based on different imaging modalities have shown that imaging measures on NAFLD might have predicting values in early diagnosis of CVD. ${ }^{19,20}$ In this regard, magnetic resonance imaging (MRI) possesses higher predicting values in predicting NAFLD, whereas ultrasound imaging might not be as sensitive for NAFLD diagnosis. In MRI, the main feature used for NAFLD diagnosis is hepatic fat concentration. The quantities of liver fat have been reportedly a reliable predicting measure of MetS and CVD risk. Loomba and colleagues 21 investigated the predicting value of quantified liver fat measured by MRI and measuring proton-density-fat-fraction (MRIPDFF) in patients with NAFLD. They reported that high PDFF on MRI in patients with NAFLD could be a predictor of MetS and increased cardiovascular risks.$^{21}$ Liver biopsy is the gold standard method for the diagnosis of NAFLD. Some studies have shown that patients with biopsy-proven NAFLD have higher total mortality rates in comparison with the general population. Söderberg and co-workers ${ }^{22}$ observed that patients with biopsy-proven NASH had a higher level of mortality from CVD. In CVD cases, the overall survival rate in patients with NASH is lower than the general population. They observed only subjects with NASH had significantly reduced survival rate. ${ }^{1,19,22}$

\section{Which Came First, NAFLD or CVD?}

NAFLD representing a broad spectrum of hepatic damage is recognized as a significant public health problem worldwide and is the most common form of liver disease represented in different forms, including simple steatosis, NASH, advanced fibrosis, and cirrhosis. NAFLD is the hepatic manifestation of MetS with the major components of IR, atherogenic dyslipidemia, abdominal obesity, and hypertension. ${ }^{28}$ MetS is a deteriorating and lethal endocrinopathy constituting an integrated chain of systemic disorders like abdominal obesity, glucose intolerance, diabetes mellitus (DM), dyslipidemia, hypertension, and CAD. Keramati and colleagues studied three large families with a syndrome of early-onset CAD, central obesity, high blood pressure, T2DM, and moderately elevated fasting triglyceride serum levels. They used WES (Whole Exome Sequencing) to analyze genes and found a mutation in DYRK1B, which substituted cysteine for arginine at position 102 in a kinase-like domain. This mutation was present in each affected family member, but it was absent in unaffected family members and unrelated controls. In the end, they suggested that DYRK1B was a crucial element in disrupted biological pathways in the disorder called MetS. ${ }^{29-32}$

Current literature reveals that NAFLD could potentially lead to excess risk for CVD-related morbidity and mortality. ${ }^{7,33} \mathrm{Wu}$ and others conducted a large meta-analysis reviewing 34 studies that reported a moderate association between NAFLD and increased CVD risk, particularly increased risk for coronary artery disease and hypertension. Contrary, this study showed no association between NAFLD 
and CVD-related mortality. ${ }^{34}$ Most of these studies included patients with underlying risk factors for CVD, including smoking and T2DM, yet the significant associations of NAFLD persisted despite controlling for these risk factors. ${ }^{34}$ Similarly, Wong and colleagues in a large prospective cohort study observed a higher prevalence of coronary artery stenosis in patients with NAFLD compared with peers without NAFLD. ${ }^{2}$ However, they observed no significant difference in the incidence of composite cardiovascular outcomes between patients with and without NAFLD. This is while the composite cardiovascular outcome was primarily associated with T2DM. ${ }^{2}$ Patients with NAFLD experience higher CVD-related mortality than the general population. ${ }^{1,5,22}$ Several studies with large sample sizes have confirmed this association. ${ }^{1,5,22}$ Adams and others studied 420 patients with NAFLD and observed that ischemic heart disease was the main cause in $25 \%$ of all deaths in these patients. ${ }^{1,35}$ Ekstedt and co-workers reported that CVD was the leading cause of death in patients with NAFLD, and the CVD related mortality rate was significantly higher than the general population. ${ }^{5}$ Matteoni and colleagues reported that CVD and malignancy were the leading causes of mortality in NAFLD. ${ }^{6}$ The impact of CVD on NAFLD is significantly correlated with T2DM, as several studies have reported T2DM as a significant covariate in patients with NAFLD. The presence of T2DM or impaired glucose tolerance has been reported as an independent predictor of increased mortality in patients with NAFLD compared with the general population. ${ }^{1,35}$ Ekstedt and colleagues observed that $78 \%$ of patients with NAFLD also suffered from impaired glucose at follow-up visits and concluded that NAFLD progression was closely associated with T2DM. The pivotal role of CVD and its associated metabolic cofactors (diabetes or impaired glucose) in mortality of patients with NAFLD represents an essential contrast with patients with other chronic liver diseases, such as hepatitis $\mathrm{C}$ infection, in whom mortality is driven by liver-related outcomes ${ }^{1}$ (table 1 ).

Atherosclerosis is the main triggering stage for the development of vascular diseases. This stage can be detected in its subclinical phase using different methods. The first stage of subclinical atherosclerosis is endothelial dysfunction. Two relevant biomarkers of vascular disease are carotid intima-media thickness (CIMT) and the presence of carotid plaques. Another biomarker of atherosclerosis is coronary artery calcification (CAC) that represents the atherosclerotic burden in arterial beds and can be diagnosed with multi-slice computed tomography (CT). CAC has been reportedly associated with CAD and increased risk of poor cardiovascular outcomes. ${ }^{9}$ Several studies have revealed that NAFLD is associated with coronary artery calcium score (CACS) (table 2). Assy and colleagues in a large cohort study, observed a strong relationship between NAFLD and CAC. ${ }^{11}$ An interesting finding of this extensive study was that the NAFLD-CACS association was independent of the traditional risk factors for CAD. ${ }^{11}$ The presence of NAFLD was associated with an increased level of non-calcified coronary plaques, which was independent of metabolic syndrome. Another research showed a significant association in patients with NAFLD and the appearance of plaques on coronary artery imaging . 36,37

\section{Pathophysiological Mechanisms of CVD- NAFLD Association}

\section{General Considerations}

The role of NAFLD as an independent risk factor of CVD is not fully confirmed. Several studies have reported increased $\mathrm{CV}$ mortality in patients with NAFLD. ${ }^{22,23}$ On the contrary, some studies with large sample sizes and long-term follow-ups did not support these findings. ${ }^{44,45}$ Therefore, findings on the association between CVD and increased risk in patients with NAFLD should be interpreted with caution, and there should be more studies in this regard.

NAFLD, abdominal obesity, and IR contribute to increased risk of CVD, but the exact causal relationships between NAFLD and CVD are still unclear. Hepatic necro-inflammation has been reported as an independent atherogenic mechanism that could possibly elevate the CVD risk in patients with NASH than the patients with simple steatosis. ${ }^{46-48}$ Elevated liver enzymes are considered as signals of hepatic necro-inflammation that could act as a marker 
Table 1: Epidemiological Studies on Cardiovascular Risk in NAFLD

\begin{tabular}{|c|c|c|c|c|c|}
\hline Study ID & Population & Study design & Diagnosis & $\begin{array}{c}\text { Follow-up } \\
\text { (Years) }\end{array}$ & Outcomes \\
\hline $\begin{array}{l}\text { Ekstedt et al } \\
92015)^{23}\end{array}$ & $\begin{array}{l}\mathrm{n}=229 \text { Swedish } \\
\text { patients; mean age } \\
49 \mathrm{yr}, 66 \% \text { men }\end{array}$ & $\begin{array}{l}\text { Retrospective } \\
\text { cohort study }\end{array}$ & Histology & 26.4 (mean) & $\begin{array}{c}\text { Total deaths: } 96 \\
\text { CVD deaths: } 41 \\
\text { Higher CVD- mortality in NAFLD } \\
\text { Histology fibrosis stage: predictor of } \\
\text { CVD mortality }\end{array}$ \\
\hline $\begin{array}{l}\text { Ekstedt et } \mathrm{al}^{5} \\
(2006)\end{array}$ & $\begin{array}{l}\mathrm{n}=129 \text { biopsy- } \\
\text { proven NAFLD }\end{array}$ & Cohort study & Histology & 13.7 (mean) & $\begin{array}{c}\text { Steatosis mortality: no increase, } \\
\text { Reduced survival of NASH, } \\
\text { Higher CVD mortality } \\
\text { Higher liver-related mortality }\end{array}$ \\
\hline $\begin{array}{l}\text { Soderberg } \\
\text { et } \mathrm{al}^{22} \\
(2010)\end{array}$ & $\begin{array}{l}256 \text { Swedish } \\
\text { patients with } \\
\text { NAFLD }\end{array}$ & $\begin{array}{l}\text { Retrospective } \\
\text { cohort study }\end{array}$ & Histology & 24 yr (mean) & $\begin{array}{c}\text { Total death }=113 \text { (47 NAFLD, } 37 \text { CVD, } \\
16 \text { liver diseases), } \\
\text { Higher CVD-mortality in NAFLD, } \\
\text { NAFLD: } 69 \% \text { increased mortality, } \\
\text { Steatosis: } 55 \% \text { increase, NASH: } 86 \% \\
\text { increase }\end{array}$ \\
\hline $\begin{array}{l}\text { Pickhardt et } \\
\mathrm{al}^{24}(2014)\end{array}$ & $\begin{array}{l}\mathrm{n}=282 \text { patients } \\
\text { with NAFLD } \\
\text { and } 786 \text { controls } \\
\text { without steatosis }\end{array}$ & $\begin{array}{l}\text { Retrospective } \\
\text { cohort study }\end{array}$ & $\begin{array}{c}\text { Unenhanced } \\
\text { CT }\end{array}$ & 7.5 (mean) & $\begin{array}{c}\text { Non-fatal CVD events }=73 \\
\text { No NAFLD-non-fatal CVD events as- } \\
\text { sociation }\end{array}$ \\
\hline $\begin{array}{l}\text { Zeb et al } \\
{ }^{25}(2016)\end{array}$ & $\begin{array}{l}\mathrm{n}=4119 \text { United } \\
\text { States-free of } \\
\text { CVD }\end{array}$ & $\begin{array}{l}\text { Prospective } \\
\text { cohort study }\end{array}$ & $\begin{array}{c}\text { Unenhanced } \\
\text { CT }\end{array}$ & 7.6 (mean) & $\begin{array}{c}\text { All-cause deaths }=253 \\
\text { non-fatal CVD events }=209 \text { NAFLD - } \\
\text { CVD total death association } \\
\text { NAFLD -non-fatal CVD events association }\end{array}$ \\
\hline $\begin{array}{l}\text { Kim et al }{ }^{26} \\
(2013)\end{array}$ & $\begin{array}{c}\mathrm{n}=11154 \\
\text { Unites States } \\
\text { adults }\end{array}$ & $\begin{array}{c}\text { Population-based } \\
\text { cohort }\end{array}$ & Ultrasound & 14.5 (median) & $\begin{array}{c}\text { Total deaths }=1795, \\
\text { CVD deaths }=673 \text {, } \\
\text { Histology fibrosis stage: A predictor of } \\
\text { CVD mortality, } \\
\text { No NAFLD- increased total death as- } \\
\text { sociation } \\
\text { No NAFLD-CVD death association }\end{array}$ \\
\hline $\begin{array}{l}\text { Emre et al } \\
{ }^{27}(2015)\end{array}$ & $\begin{array}{c}\mathrm{n}=186 \text { Turkish } \\
\text { non-diabetic } \\
\text { patients }\end{array}$ & $\begin{array}{l}\text { Retrospective } \\
\text { cohort study }\end{array}$ & Ultrasound & $\begin{array}{l}\text { In-hospital } \\
\text { cardiac events }\end{array}$ & $\begin{array}{l}\text { In-hospital CVD events }=32 \\
\text { CVD deaths }=8 \\
\text { NAFLD- increased in-hospital CVD } \\
\text { events association } \\
\text { No NAFLD-increased CVD death } \\
\text { association }\end{array}$ \\
\hline
\end{tabular}

Total deaths: All-cause and CVD deaths; NAFLD: Non-alcoholic fatty liver disease; CT: Computed tomography; CAC: Coronary artery calcification; CIMT: Carotid intima-media thickness; CP: Carotid plaque; DM: Diabetes mellitus; NASH: Non-alcoholic steatohepatitis.

of increased CVD risk in patients with NAFLD. ${ }^{49,50}$ Patients with NASH have reportedly had increased carotid-artery intimal medial thickness significantly higher than their peers, which in turn supports the necro-inflammation hypothesis. ${ }^{5,51,52}$ Several factors have been described as potentially pathogenic underpinnings of NAFLD-CVD associations. Metabolic disorders such as FLD and T2DM have been reported to cause a low-grade systemic inflammation leading to different extrahepatic complications, including increased risk of CVD. ${ }^{53}$ Several mechanisms have been reported as the underpinning drives of this systemic inflammation, such as oxidative stress, endoplasmic reticulum stress, lipotoxicity, and gut microbiota alterations. On the other hand, these mechanisms could be manipulated by other factors, such as genetic and epigenetic variations .${ }^{54-56}$ NAFLD and DM are common diseases that concurrently occur and could act synergistically to increase the risk of hepatic and extra-hepatic clinical outcomes, which in turn increase the risk of CVD. NAFLD affects up to $70-80 \%$ of patients with T2DM and up to $30-40 \%$ of adults with T1DM. The concurrent genesis and development of NAFLD and DM not only increases the risk of a severe form of NAFLD but also increases the risk of chronic vascular complications of diabetes mellitus. In other words, strong evidence has linked the NAFLD with 
Table 2: Studies on the Associations between NAFLD and Coronary Artery Disease and Carotid Disease

\begin{tabular}{|c|c|c|c|c|c|c|}
\hline Study ID & Population & Study Design & $\begin{array}{c}\text { Modality to } \\
\text { assess CV risk }\end{array}$ & $\begin{array}{l}\text { Diagnosis } \\
\text { of NAFLD }\end{array}$ & Outcome & $\begin{array}{c}\text { Methodologi- } \\
\text { cal quality as- } \\
\text { sessment }\end{array}$ \\
\hline $\begin{array}{l}\text { Sinn et al }{ }^{38} \\
(2016)\end{array}$ & $\begin{array}{l}\mathrm{N}=8020 \text { men }(\mathrm{av}- \\
\text { erage age, } 49.2 \mathrm{yr})\end{array}$ & $\begin{array}{l}\text { Retrospective } \\
\text { cohort study }\end{array}$ & $\begin{array}{l}\text { CIMT on ca- } \\
\text { rotid ultrasound }\end{array}$ & Ultrasound & $\begin{array}{l}\text { NAFLD increases the } \\
\text { risk of subclinical carotid } \\
\text { atherosclerosis develop- } \\
\text { ment. } \\
\text { Liver fibrosis predicts } \\
\text { subclinical carotid athero- } \\
\text { sclerosis. }\end{array}$ & \\
\hline $\begin{array}{l}\text { Pais et al }{ }^{39} \\
(2016)\end{array}$ & $\begin{array}{c}\mathrm{n}=1871(\text { mean } \\
\text { age } 53 \mathrm{yr} ; 65 \% \\
\text { men }\end{array}$ & $\begin{array}{l}\text { Longitudinal } \\
\text { cohort study }\end{array}$ & $\begin{array}{l}\text { CIMT on ca- } \\
\text { rotid ultrasound }\end{array}$ & $\begin{array}{l}\text { Fatty Liver } \\
\text { Index }\end{array}$ & $\begin{array}{l}\text { Steatosis: } 12 \% \text { of patients } \\
\text { CP: } 23 \% \text { of patients } \\
\text { CIMT is associated with } \\
\text { steatosis occurrence. } \\
\text { Steatosis predicts CP oc- } \\
\text { currence. }\end{array}$ & \\
\hline $\begin{array}{l}\text { Park et al }{ }^{40} \\
(2016)\end{array}$ & $\mathrm{n}=1732$ & $\begin{array}{l}\text { Longitudinal } \\
\text { cohort study }\end{array}$ & $\begin{array}{c}\text { Calcium } \\
\text { scoring CT to } \\
\text { assess CAC }\end{array}$ & Ultrasound & $\begin{array}{l}\text { NAFLD is a risk fac- } \\
\text { tor for CAC. NAFLD } \\
\text { increases the risk of } \\
\text { calcification. } \\
\text { Association of NAFLD } \\
\text { severity with CAC devel- } \\
\text { opment: dose-dependent }\end{array}$ & \\
\hline $\begin{array}{l}\text { Kim et } \mathrm{al}^{41} \\
(2012)\end{array}$ & $\begin{array}{c}\mathrm{n}=4023 \text { (mean } \\
\text { age, } 56.9 \pm 9.4 \mathrm{yr} \\
\quad 60.7 \% \text { men) }\end{array}$ & $\begin{array}{l}\text { Retrospective } \\
\text { chart review }\end{array}$ & $\begin{array}{c}\text { Calcium } \\
\text { scoring CT to } \\
\text { assess CAC }\end{array}$ & Ultrasound & $\begin{array}{l}\text { NAFLD increases the } \\
\text { risk of coronary athero- } \\
\text { sclerosis. } \\
\text { NAFLD might be an } \\
\text { independent risk factor } \\
\text { for CAD. }\end{array}$ & \\
\hline $\begin{array}{l}\text { Fracanzani } \\
\text { et al }{ }^{42} \\
(2016)\end{array}$ & $\begin{array}{c}\mathrm{n}=125 \text { patients } \\
\text { with NAFLD } \\
\mathrm{n}=250 \text { age and } \\
\text { sex-matched } \\
\text { controls }\end{array}$ & $\begin{array}{l}\text { Longitudinal } \\
\text { cohort study }\end{array}$ & $\begin{array}{l}\text { CIMT on ca- } \\
\text { rotid ultrasound }\end{array}$ & Ultrasound & $\begin{array}{l}\text { Major CVD in } 19 \% \text { of } \\
\text { NAFLD. Higher cumula- } \\
\text { tive CVD risk in NAFLD. } \\
\text { Plaques and steatosis are } \\
\text { the strongest predictors } \\
\text { for CVD. } \\
\text { Higher CIMT in NAFLD } \\
\text { than controls. } \\
\text { NAFLD is an indepen- } \\
\text { dent risk factor for CVD. }\end{array}$ & \\
\hline $\begin{array}{l}\text { Nahandi et } \\
\mathrm{al}^{43}(2014)\end{array}$ & $\begin{array}{c}\mathrm{n}=151 \\
\text { NAFLD+DM }=49 \\
\text { non-diabetic } \\
\text { NAFLD }=50 \\
\text { control }=52\end{array}$ & $\begin{array}{l}\text { Case control } \\
\text { study } \\
\text { group }\end{array}$ & $\begin{array}{l}\text { CIMT on ca- } \\
\text { rotid ultrasound }\end{array}$ & Ultrasound & $\begin{array}{l}\text { Significant NAFLD- ath- } \\
\text { erosclerosis association, } \\
\text { the association was inde- } \\
\text { pendent of DM. }\end{array}$ & \\
\hline
\end{tabular}

NAFLD: Non-alcoholic fatty liver disease; CT: Computed tomography; CAC: Coronary artery calcification; CIMT: Carotid intima-media thickness; CP: Carotid plaque; DM: Diabetes mellitus

an increased risk of developing CVD and other cardiac and arrhythmic complications in patients with T1DM or T2DM. NAFLD is also associated with an increased risk of developing microvascular diabetic complications, especially chronic kidney disease.

\section{Proposed mechanism of CVD in NAFLD}

NAFLD is a part of a complex multisystem disorder with multiple bidirectional relationships. Moreover, each patient possesses his/her own combinations of the causal mechanisms of two or more parameters.
Several mechanisms have been reported as the pathophysiological underpinnings of CVD development in patients with NAFLD. These mechanisms are complex and often interrelated, and most of them are not yet completely understood. Some of these mechanisms are structural alterations of cardiovascular system, endothelial dysfunction, homocysteine and oxidative stress, lipid profile, IR, atherogenic dyslipidemia, angiogenic factors, hemostasis, chronic inflammation and cytokines, hepatokines, adipokines, gut-liver axis, reduced adiponectin levels, manipulated synthesis of 
anti-coagulant and pro-coagulant factors, and genetic background. ${ }^{2,25,48,57,58}$ The interesting evidence reported by different studies is that these mechanisms work synergistically, or all of these mechanisms concurrently contribute to this disorder. NAFLD is strongly associated with hepatic and adipose tissue IR regardless of its stage. In other words, liver fat content could be utilized as an independent predictor measure of IR . ${ }^{59,60}$ NAFLD, particularly in the necroinflammatory stage, can lead to atherogenic dyslipidemia. ${ }^{60}$ Moreover, in this disorder, the levels of pro-coagulant factors like tumor growth factor, plasminogen activator inhibitor-1, and fibrinogen are increased, which all of these factors consequently increase the risk of atherosclerosis. ${ }^{41}$ NAFLD has chronic subclinical inflammation, which is associated with several inflammatory markers. Increased vascular risk is related to increased levels of inflammatory cytokines and markers such as IL-6 (Interleukin 6), TNF (Tumor Necrosis Factor), CRP (C-reactive protein), and fibrinogen. Oxidative stress has been reported to play a role in increasing CVD risk in patients with NAFLD by triggering the changes in endothelial function to lead to the formation and deposition of oxidized LDL in the sub-intimal space. ${ }^{38}$

Oxidation is an essential process for the human body to fight pathogens, while oxidative stress, a marker of NAFLD, is caused by an alteration of the free radical and antioxidant activity. This imbalance could result in multiple dysfunctions and disorders due to the abnormal release of cytokines such as TNF- $\alpha$, CRP, and IL-6. Studies have demonstrated that oxidative stress could be involved in the pathogenesis of CVD in patients with NAFLD through these processes while contributing to the progression of liver disease severity from simple steatosis to steatohepatitis. ${ }^{14,61,62}$

The IR is defined as an abnormal cell response to insulin hormone and is the main risk factor strongly associated with NAFLD, atherosclerosis, and MetS. Some evidence has demonstrated that IR development and evolution is the main risk factor that initiates the NAFLD process through modifications and alterations of metabolism of glucose, fatty acid, and lipoprotein. ${ }^{63}$ Furthermore, several studies have revealed that hyperinsulinemia could alter cardiomet- abolic cascade through deteriorating insulin signaling pathways and abnormal IR in involved tissues. ${ }^{64}$ The altered adipokines, subclinical inflammation, and increased ectopic fat accumulation in tissues and organs can further intensify IR, which is associated with an increased risk of adverse CVDs.

To determine other specific mechanisms through which NAFLD may contribute to the development and progression of CVD, further genotypic and phenotypic studies with large sample sizes are needed . 2,42,65

The Burden of Evidence on NAFLD and the Risk of Cardiovascular Events

\section{Cardiovascular Risk Assessment in NAFLD}

CVD and NAFLD are related through multiple pathophysiological mechanisms. ${ }^{66}$ NAFLD increases the risk of CVD through different mechanisms, including systemic inflammation, oxidative stress, endothelial dysfunction, hepatic IR, and altered lipid metabolism. ${ }^{66-68}$ The assessment of CVD in all patients with NAFLD should be evaluated for the risk, which should be done annually or biannually. Patients should be evaluated for traditional CVD risk factors, including obesity, dyslipidemia, diabetes, and high blood pressure. Fasting glucose or glycosylated hemoglobin level should be assessed on the initial visit to diagnose DM. MetS is a common dysfunction in patients with NAFLD, which is associated with an increased risk of CVD and allcause mortality. Therefore, assessment for MetS is an important component of $\mathrm{CV}$ risk stratification. According to the National Cholesterol Education Program (NCEP) regulations, MetS is defined as the presence of three or more of the following conditions: (1) increased triglyceride levels ( $\geq 150$ $\mathrm{mg} / \mathrm{dL})$; (2) low HDL level $(<40 \mathrm{mg} / \mathrm{dL}$ in men, $<$ $50 \mathrm{mg} / \mathrm{dL}$ in women); (3) increased fasting glucose level ( $\geq 110 \mathrm{mg} / \mathrm{dL})$; (4) hypertension $(\geq 130 / 85$ $\mathrm{mm} \mathrm{Hg}$ or on antihypertensive medication); and (5) abdominal obesity (waist circumference: $>102 \mathrm{~cm}$ in men, $>88 \mathrm{~cm}$ in women).

Several methods are used in the general population to estimate CVD risks, including the Framingham 
Risk Score (FRS). The FRS is a validated measure of $\mathrm{CV}$ risks in the general population. The FRS estimates an individual's 10-year risk of myocardial infarction or CVD death and incorporates age, sex, cholesterol level, HDL level, smoking status, and hypertension. Moreover, the FRS has been validated as a predictor of CVD in NAFLD and should be used to risk-stratify individuals and guide the treatment of risk factors like dyslipidemia. Recently, the American Heart Association recommended a new cardiovascular assessment tool for the prediction of atherosclerotic cardiovascular disease. This score incorporates the common risk factors for CVD but needs to be validated in patients with NAFLD. ${ }^{69}$ Lazarus and colleagues conducted a survey on NAFLD with experts in European countries, coupled with data extracted from official documents on policies, clinical guidelines, awareness, and monitoring. ${ }^{70}$ They aimed to determine whether European countries had implemented an adequate public health response to NAFLD and NASH. They observed a general lack of national policies, awareness campaigns, and civil society involvement, and few epidemiological registries. This includes policy in the form of a strategy, clinical guidelines, awareness campaigns, civil society involvement, and health systems organization including registries. ${ }^{70}$ Singh and colleagues investigated the interplay between Wnt (The Wnt signaling pathway is an ancient and evolutionarily conserved pathway that regulates crucial aspects of cell fate determination, cell migration, cell polarity, neural patterning and organogenesis during embryonic development.) and insulin signaling pathways in skeletal muscles and skin fibroblasts of healthy non-diabetic LRP6R611C mutation carriers. LRP6 mutation carriers exhibited hyperinsulinemia and reduced insulin sensitivity compared with the noncarrier relatives in response to oral glucose ingestion. They also reported that LRP6R611C mutation reduced TCF7L2-dependent transcription of the insulin receptor, while it increased the stability of IGFR and enhanced mTORC1 activity. They concluded that Wnt/LRP6/TCF7L2 axis serves as a regulator of glucose metabolism and a potential therapeutic target for IR..$^{71}$ Although research is ongoing on developing new effective medications for the treatment of different $\mathrm{CV}$ events associated with liver dysfunctions, ${ }^{72}$ it is necessary to develop genetic and epigenetic based risk assessment tools for CVD in patients with NAFLD.

Genetic Factors Involved in NAFLD-CVD Association

NAFLD is epidemiologically associated with being overweight, IR features, and T2DM, which progresses to advanced liver fibrosis and hepatocellular carcinoma. Genetic factors play an important role in the genesis and progression of NAFLD. Several common naturally occurring genes and genetic polymorphisms modulating lipid and retinol metabolism in hepatocytes increase the risk of NAFLD development and progression. $^{73}$

There is increasing evidence demonstrating the impacts of genetic modifiers on NAFLD development and NAFLD-CVD associations. NAFLD occurs and is developed in the context of systemic metabolic dysfunction that concurrently intensifies the risk of CVD and diabetes. These interrelated conditions reportedly possess a heritable component. Several genes and polymorphisms have been reported to contribute to NAFLD genesis, development and its severity.

Chronic oxidative stress is considered one of the key mechanisms responsible for both liver damage progression in NAFLD and atherosclerotic disease. The molecular mechanisms and genetic pathways involved in these genetic variants with the liver disorder have not yet been fully elucidated. However, hepatic fat has been introduced as a crucial triggering agent of the disease and altered retinol metabolism and mitochondrial oxidative stress have a pivotal role in predicting or determining the progression to severe NAFLD.

Evidence from familial clustering, twin studies, and ethnic differences has revealed that genetic factors contribute to $18-50 \%$ of NAFLD development and development of CVD in patients with NAFLD..$^{55,73,74}$ A large twin study on the association of NAFLD with CVD risk did not find any association between genetic com- 
ponents and NAFLD development, notwithstanding more development in patients with NAFLD.$^{32,55,75,76}$ However, so far, the role and contribution of few genes have been confirmed through robust validation or transmission disequilibrium assessment. $48,50,55,77,78$ Of these genes and polymorphisms, patatinlike phospholipase domain-containing protein 3 (PNPLA3), transmembrane 6 superfamily member 2 (TM6SF2), hydroxysteroid 17-beta dehydrogenase 13 (HSD17B13), adiponectin-encoding gene (ADIPOQ), apolipoprotein C3 (APOC3), peroxisome proliferatoractivated receptors (PPAR), leptin receptor (LEPR), sterol regulatory element-binding proteins (SREBP), tumor necrosis factor-alpha (TNF- $\alpha$ ), microsomal triglyceride transfer protein (MTTP), manganese superoxide dismutase (MnSOD), and membrane-bound O-acyltransferase domain-containing 7 (MBOAT7) are the most documented ones. In the following sections, the current evidence on the genetic components of NAFLD genesis and development and also genetic components on the NAFLD -CVD associations are discussed.

\section{PNPLA3 and HSD17B13}

Different well designed studies have demonstrated the association between PNPLA3 rs738409 mutation and the severity of NAFLD. ${ }^{79,80}$ The function of PNPLA3 gene has been reported to have a direct relation with triglyceride metabolism, whereas mutations have not been associated with IR or glucose intolerance. PNPLA3 mutation has been established as a modifier of NAFLD ${ }^{55}$ in terms of disease severity and the risk on NAFLD-related hepatocellular carcinoma $(\mathrm{HCC})^{81}$, whereas the link of this mutation with the CVDs is still unclear. ${ }^{2,7,11,19,75}$ Genome-wide association studies (GWASs) have revealed the main genetic determinants of NAFLD and hepatic fat content. The rs738409 C > G single nucleotide polymorphism (SNP) that encodes for the I148M protein variant of PNPLA3 is the one with the most significant impact. Previously, a GWAS conducted in a large multi-ethnic population has demonstrated that the I148M variant is the most common variant in the Hispanics, which is the most susceptible group to NAFLD. ${ }^{79}$

Lifestyle-related parameters, such as inactive daily-life and intake of fructose-enriched drinks, are associated with the I148M variant in driving buildup of hepatic fat and thus NAFLD progression, particularly in pediatric patients. ${ }^{82,83}$ However, hyper-adiposity is the primary environmental factor triggering the phenotypic expression of $1148 \mathrm{M}$ PNPLA3 variant in individuals with no excess alcohol consumption. ${ }^{84}$ Thus, environmental factors, such as adiposity contribute to NAFLD progression by interacting with genetic risk variants. The functional data showed that PNPLA3 is a predisposition agent to NAFLD triggered by an epidemiological interaction between adiposity and genetic variants. Under the obesity and IR conditions, insulin, hepatocytes, and hepatic stellate cells trigger the PNPLA3 expression at the surface of lipid droplets. ${ }^{85}$ The PNPLA3 promoter transports a particular harmonized site for the Sterol regulatory element-binding protein 1c (SREBP-1c) elicited by insulin. ${ }^{86,87,88}$ Liver $X$ receptor (LXR) mediates SREBP-1c upregulation so that LXR agonist treatment increases PNPLA3 mRNA levels. ${ }^{89,90}$ Under the hyperinsulinemia condition associated with excess adiposity, the mutated I148M PNPLA3 protein is built upon the surface of lipid droplets, where it is not catalytically active, and escapes ubiquitylation altering triglycerides and phospho-lipids turnover and remodeling. ${ }^{91,92}$ This mechanism is partly manipulated by the ability of the PNPLA3 variant to eliminate CGI-58, as an essential cofactor for the function of ATGL/ PNPLA2, the main triglycerides hydrolase of hepatocellular lipid droplets. ${ }^{93,94}$

Furthermore, the PNPLA3 protein is involved in the release of retinyl-palmitate, the storage form of retinol, whose metabolites are involved in the regulation of gene transcription through binding nuclear hormone receptors (RAR/RXR). Hepatic stellate cells (HSC) are the main cellular site of retinol storage in the human body and a pivotal player in the liver fibrogenic process. HSC under the impaired PNPLA3 expression reduces retinol release. The I148M variant decreases the PNPLA3 retinyl- 
palmitate lipase activity, which results in higher fat content in HSC droplets, and is related to a proinflammatory and profibrogenic phenotype. ${ }^{95,96}$ In addition to steatosis, HSC induced manipulations in the retinol release could lead to hepatic inflammation, fibrogenesis, and carcinogenesis.

In line with a major role retinol plays in the pathogenesis of progressive NAFLD, a recent study in large cohorts of individuals from general population demonstrated that an SNP in hydroxysteroid 17beta dehydrogenase 13 (HSD17B13, rs72613567), encoding for a splice variant, was associated with protection against both alcoholic and non-alcoholic fatty liver disease at exome-wide level. ${ }^{97}$ The protein is expressed on the surface of hepatocellular lipid droplets, and the variant generates a truncated unstable protein, which reduces HSD17B13 enzymatic activity. ${ }^{97}$ An interesting finding was that carriers of the PNPLA3 I148M variant showed more significant protection against NAFLD than the control peers, suggesting that both risk factors interact in the pathogenesis of this condition. The pivotal role of HSD17B13 in NAFLD predisposition has been confirmed already. ${ }^{98}$ In a study of 429 patients with NAFLD and 180 controls from South America, the minor rs72613567 allele showed protection against NASH and fibrosis. The spliced variant was related to decreased HSD17B13 levels in hepatocytes. ${ }^{98}$

A study showed that another variant in HSD17B13 (rs62305723, encoding for the p.P260S aminoacidic substitution) was associated with reduced inflammation and ballooning in patients with histological NAFLD. ${ }^{99}$ A major discovery was that HSD17B13 protein has retinol dehydrogenase (RDH) activity, depending on the availability of cofactors and on the correct targeting to lipid droplets. ${ }^{100}$ Both rs72613567 splice variant and rs62305723 p.P260S variant resulted in the loss of enzymatic activity and protection against liver damage associated with NAFLD. ${ }^{99,101}$

Both PNPLA3 and HSD17B13 proteins are involved in retinol metabolism; thus, their genetic variations influencing retinol metabolism at the level of HSC or hepatocytes lipid droplets could potentially play a role in NAFLD progression. ${ }^{100}$ Thus, the remodeling of specific lipids and retinol plays a pivotal role in NAFLD development and contributing to fat accumulation, inflammation, and fibrogenesis.

\section{Adiponectin-encoding Gene (ADIPOQ)}

Adiponectin is an adipose tissue hormone that regulates energy homeostasis in different organs and at the cellular level. ${ }^{30,31,102}$ Several studies have reported that adiponectin might play a possible role in the development and progression of NAFLD through PPAR $\gamma$ pathway. Adiponectin-encoding gene (ADIPOQ) is located on chromosome 3q27 and encodes the adiponectin protein that is an adipocyte-derived hormone with three main functions of anti-diabetic, anti-atherogenic, and anti-inflammatory properties. Adiponectin protein increases insulin sensitivity of the liver, which in turn suppresses IR. Adiponectin increases the secretion of endothelial nitric oxide (NO) and inhibits monocyte adhesion and smooth muscle cell proliferation in the vascular wall. ${ }^{47,103}$ ADIPOQ acts as a biomarker for the initiation and severity of NAFLD disorder, in which adiponectin systemic levels are decreased. ${ }^{30}$ Different polymorphism genes have been reportedly associated with susceptibility to NAFLD. ${ }^{30}$ Adiponectin rs266729 (-11377C/G) polymorphism might be a candidate gene, which determines NAFLD susceptibility. ${ }^{104}$ Some studies have demonstrated that two functional polymorphisms of ADIPOQ, including rs266729 and rs2241766 (+45 T/G), are associated with the induction and development of NAFLD as well as its severity. Moreover, the presence of $\mathrm{G}$ allele at loci -11377 has been correlated with the level of necro-inflammation and at position +45 , which consequently resulted in reduced plasma adiponectin levels in patients, indicating the association of ADIPOQ rs266729 and rs2241766 polymorphisms in NAFLD pathogenesis and progression. ${ }^{51}$ The $\mathrm{G}$ allele of rs266729 is associated with a reduced level of serum adiponectin, which could result in precipitation of liver steatosis in patients with T2DM. Therefore, the gene polymorphism of adiponectin rs266729 is strongly correlated with NAFLD risk. ${ }^{75}$ The ADIPOQ expression is significantly decreased in epicardial adipose tissue and paracardial adipose tissue in 
patients with MetS and CAD. ${ }^{105}$ Different studies have demonstrated that in the Afro-Caribbean patients with T2DM, rs2241766 was associated with CAD. ${ }^{106}$ Reviewing several studies showed that ADIPOQ gene polymorphisms of rs266729, rs2241766, and rs1501299 $(+276 \mathrm{G}>\mathrm{T})$ are associated with CVD, and the level of associations was not significant. The rs266729 G allele and rs2241766 $\mathrm{G}$ allele are associated with the increased CVD risk, whereas the rs1501299 $\mathrm{T}$ allele is negatively associated with CVD risk. ${ }^{107}$ ADIPOQ rs1501299 gene polymorphism is associated with CAD, and the SNP has different sex-dependent effects on adiponectin levels and lipoprotein metabolism, considering the detrimental effect that the rare homozygous genotype (TT) was associated with higher levels of total cholesterol (TC) and low-density lipoprotein cholesterol (LDL-C) compared with the common homozygous genotypes (GG) and heterozygous one. However, the influences of ADIPOQ rs1501299 polymorphism on the levels of biochemical markers were independent of the adiponectin circulating level. ${ }^{102,108}$

\section{Leptin Receptor Gene (LEPR)}

Leptin acts through the leptin receptor (LepR), which is encoded by a single gene on the chromosome 1 p31 called the leptin receptor gene (LEPR). The polymorphism of LEPR 3057G $>$ A (rs1805096) has been reportedly associated with the trigger of NAFLD through manipulating lipid metabolism and influencing the liver insulin sensitivity. ${ }^{109}$ Different studies have demonstrated that in patients with NAFLD, the Lys656Asn (rs8179183) polymorphism of LEPR is associated with IR and glucose levels. ${ }^{110}$ In a study conducted on the Japanese population, it was reported that LEPR polymorphism rs1137101 was associated with total cholesterol, high-density lipoprotein cholesterol (HDLC), and LDL-C levels and this polymorphism contributes mainly to alteration of Gln223Arg at the protein level. ${ }^{111}$ Polymorphisms of LEPR G1n223Arg (G/G) are associated with the increased NAFLD risk so that the genetic polymorphisms of Gln223Arg significantly interact with the enhanced risk of NAFLD. ${ }^{109,112}$ Gln223Arg polymorphism of the LEPR is positively associated with the risk of familial combined hyperlipidemia, which in turn is associated with premature CVD indicated by low HDL-C. ${ }^{113}$ Several studies on different ethnic groups have demonstrated that the expressions of LEPR rs1137100 are associated with increased risk of NAFLD and NASH. Furthermore, this polymorphism has been reportedly associated with simple steatosis and NASH without significant fibrosis. ${ }^{88}$ Different studies conducted on Japanese obese populations have reported that patients with GG genotype have a significantly lower total and LDL cholesterol. ${ }^{114}$ An SNP rs1137100 of LEPR could alter the Lys109Arg at the protein level, which is associated with several CVD risk factors such as body mass index (BMI), impaired glucose tolerance, systolic blood pressure (SBP), and insulin sensitivity. ${ }^{115-117}$ A study conducted by Okada and colleagues on Japanese obese children showed that the presence of Arg109 is associated with the levels of serum lipids. ${ }^{114}$ The persons with the Arg109Arg genotype or some other linked polymorphisms have been reported to be protected against CVDs as well as against total mortality, and these associations are independent of the traditional CAD risk factors. ${ }^{118}$

\section{Apolipoprotein C3 Gene}

Apolipoprotein C3 gene (APOC3)'s location is on chromosome 11q23. APOC3 protein is mainly synthesized in the liver and to some extent, in the intestine. It is a component of triglyceride (TG)-rich lipoproteins and HDL. This gene is involved in the transport and clearance of chylomicron remnants, VLDL, and HDL from the bloodstream. ${ }^{119,120} \mathrm{~A}$ prospective case-control study with a large sample size conducted in the southern Han Chinese population showed that carriers of the $\mathrm{C}$ allele (TC or $\mathrm{CC}$ ) of the apolipoprotein gene are at a higher risk of IR than the control population. This finding supports the finding of another study conducted on the Indian population. ${ }^{121}$ The polymorphisms -482 C/T (rs2854117) and -455 T/C (rs2854116) in APOC3 were associated with NAFLD and IR. ${ }^{121}$ The $-455 \mathrm{~T}>\mathrm{C}$ conversion is located in a putative insulin-response element of APOC3, which is related 
to plasma TG levels. ${ }^{122-124}$ A prospective case-control study involving 600 participants, including 300 patients with NAFLD and 300 controls, indicated that APOC3 rs2854116 genetic variations involved in the susceptibility to develop NAFLD, IR, hypertriglyceridemia, and low HDL in the southern Chinese Han population. ${ }^{125}$ A meta-analysis of 20 studies with 15,591 participants showed that APOC3 Sst I and rs2854116 polymorphisms might be associated with the risk of CAD. ${ }^{126}$ Ding and colleagues observed a close association between the minor alleles of APOC3-455 T/C polymorphisms and acute coronary syndrome in which the $\mathrm{C}$ allele was associated with higher TG and lower HDL cholesterol. ${ }^{127}$ These findings demonstrated an association between APOC3 and increased risk of CAD by altering lipid metabolism. Polymorphic variants preclude insulin binding and enhancing the transcription and synthesis of APOC3, which increases the circulating APOC3 concentration and functions as an apolipoprotein lipase inhibitor and thus impedes the clearance of TG-rich particles leading to hypertriglyceridemia, ${ }^{128,129}$ The liver, through a receptor-mediated process, preferentially degrades the TG-rich circulating particles resulting in NAFLD and hepatic IR , 49,130,131 However, a study in the Chinese Han population reported that T-455C at rs2854116 and C-482 T at rs2854117 in APOC3 were not associated with NAFLD, did not even contribute to the inter-individual differences in lipid profiles, IR, obesity, oxidative stress, and susceptibility to NAFLD. ${ }^{132}$ A case-control study showed a significant association between APOC3 3238G allele and increasing plasma TG and VLDL-C levels, and a higher risk of CAD through lipid metabolism. ${ }^{133}$

\section{Peroxisome Proliferator-activated Receptors Gene (PPAR)}

There are three members of the PPAR family, which are encoded by a different gene: PPAR (NR1C1), PPAR (NR1C3), and PPAR (NP1C2). Carriers of the PPAR $\gamma$ Ala allele showed increased resistance to the development and progression of NAFLD by resisting to oxidative stress. ${ }^{134,135}$ A Meta-analysis showed a protective role for the Ala allele of the
PPAR $\gamma$ Pro12Ala (rs1801282) polymorphism in NAFLD risk, ${ }^{136}$ and rs1801282 polymorphism is associated with susceptibility to NAFLD in East Asians, but not in European populations. ${ }^{136}$ Domenici and colleagues showed that 12 Ala allele of PPAR $\gamma$ was not associated with NASH occurrence as it was less prevalent in these patients compared with the healthy control group. There were no links between PPAR $\gamma$ SNPs (rs1801282) and clinical, laboratory, and histological parameters in patients with NAFLD, which suggest that SNP rs1801282 may result in protection against liver injury. ${ }^{137}$ Leu162Val (rs1800206) PPAR $\alpha$ SNP may be involved in the progression of NAFLD, whereas the carriers have more advanced fibrosis. ${ }^{138}$ Wang and colleagues reported no association between PPAR $\gamma$ rs 1801282 polymorphism and NAFLD risk in both Asian and Caucasian populations. ${ }^{138}$ A study demonstrated that rs1800206 in PPAR $\alpha$ was significantly associated with lipoprotein (a) ( $\mathrm{Lp}(\mathrm{a}))$, which is an LDL-like particle that can increase the risk of atherosclerosis independently and thus is the risk factor of CAD. ${ }^{139,140}$ The Ala 12 Ala genotype of the PPAR $\gamma 2$ might decrease the number of affected vessels and CAD severity, which could be attributed to a direct antiatherogenic effect of this polymorphism as well as an indirect effect on lowering the inflammatory parameters and IR. ${ }^{141}$ SNP rs3856806, also known as C161T or C1431T, in the PPAR $\gamma$ was significantly associated with fasted serum lipid profile in patients with CAD. ${ }^{142}$ Wan and co-workers indicate that the PPAR $\gamma$ rs3856806 polymorphism may reduce the risk of severe atherogenesis through modulation of adipose metabolism in Chinese patients with CAD. ${ }^{143}$ Recent evidence has revealed the association between SNP rs3856806 and a higher susceptibility to NAFLD through the adiponectin pathway. ${ }^{32,144}$

Sterol Regulatory Element-Binding Proteins (SREBPs)/Sterol Regulatory Element-Binding Transcription Factors (SREBFs) Gene

Three isoforms of SREBPs are encoded by SREBP-1 (SREBF-1) and SREBP-2 (SREBF-2) genes. SREBP-1 genes contribute to the biosynthe- 
sis of cholesterol, unsaturated fatty acid, triglyceride, phospholipid, and lipid uptake. ${ }^{145,146}$ SREBF-1c rs11868035 polymorphism is associated with an increased risk of NAFLD development with more severe liver impairments in glucose and lipoprotein metabolism that contribute to NAFLD genesis and development. ${ }^{31}$ SREBP-1c modulates the genetic susceptibility to the whole spectrum of health-related risks in NAFLD by extensively affecting multiple metabolic steps at hepatic and extra-hepatic sites. The SNP rs11868035, which is associated with impaired glucose homeostasis, lipoprotein, and adiponectin responses to fat ingestion, was correlated with the severity of steatosis and necro-inflammation and the presence of NASH. ${ }^{31}$ It is also associated with CAD risk by modulating the changes in endothelial adhesion molecules. ${ }^{147,148}$ SREBP-2 is encoded by a separate gene located on human chromosome $22 \mathrm{q} 13$, which plays a significant role in the maintenance of lipid homeostasis by stimulating the expression of genes correlated with the cholesterol biosynthetic pathways. ${ }^{149,150}$ Activation of SREBP-2 may play a major role in enhancing the uptake of cholesterol, and biosynthesis can also be directly involved in the regulation of cholesterol metabolism in cells, thereby maintaining cholesterol homeostasis. ${ }^{151}$ Recent evidence has demonstrated a significant association between SREBP-2 polymorphisms and FLD development, and IR, and could lead to hypertriglyceridemia. ${ }^{152,153}$ A casecontrol study in the Han Chinese population provided evidence that the GG genotype and $\mathrm{G}$ carrier $(\mathrm{CG}+\mathrm{GG})$ of rs2228314 $\mathrm{G}>\mathrm{C}$ polymorphism in SREBP-2 may increase the risk of NAFLD. Therefore, SREBP-2 rs2228314 G>C polymorphism may be a potential biomarker for NAFLD. ${ }^{154}$ A study from Eastern China shows that rs2228314 has no association with the risk of premature CAD nor the extent of coronary lesions. ${ }^{155}$ Further studies are required in this field. The $\mathrm{C}$ allele and the G/C genotype of SREBP-2 rs2228314 were associated with an increased risk of NAFLD in Asian Indians. The G/C genotype of SREBP-2 is significantly associated with serum levels of TG, elevated CRP, fasting insulin, and homeostasis model assessment for IR levels. Therefore, this polymorphism could explain the close relationship between IR, TG, CRP, and SREBP-2 polymorphism. ${ }^{156}$ The functional SNP rs $133291 \mathrm{C} / \mathrm{T}$ in the SREBF-2 gene has been linked to serum LDL cholesterol. ${ }^{157}$ SREBF-1c SNPs and SREBF-2 SNPs predicted the 7-year incidence of NAFLD, diabetes, and endothelial dysfunction markers at the end of follow-up in non-obese, nondiabetic, insulin-sensitive subjects without MetS at baseline. In patients with biopsy-proven NAFLD, SREBF-2 was significantly associated with the presence of NASH and extensively affected tissue insulin sensitivity, pancreatic $\beta$-cell function, and lipoprotein and adipokine responses to fat ingestion. The SREBF-1c SNP is associated with impaired glucose homeostasis as well as lipoprotein and adiponectin responses to fat ingestion. This polymorphism was also associated with the presence of NASH and the severity of steatosis and necroinflammation. ${ }^{31,148}$

Transmembrane 6 Superfamily Member 2 Gene (TM6SF2)

TM6SF2 is a non-synonymous SNP that has been associated with NAFLD and fibrosis..$^{54}$ Mutation of the TM6SF2 gene could result in accommodation of triglyceride and cholesterol in the liver, which consequently predisposes the patients to fibrosis and NAFLD. ${ }^{78}$ On the contrary, TM6SF2 mutation has been associated with reduced VLDL release and increased serum triglyceride while insulin sensitivity remains unaltered. ${ }^{158,159}$ It seems that the TM6SF2 mutation, also known as the Catch-22 paradigm, functions as a cardioprotective agent rather than a deteriorating agent for the CV system. ${ }^{56}$ TM6SF2 (rs58542926 c.449 $\mathrm{C}>\mathrm{T}$ ) at the position $19 \mathrm{p} 13.11$ is correlated with hepatic steatosis through a human exome chip. ${ }^{78}$ Exome-wide association studies demonstrated that the TM6SF2 rs58542926 C > T variant, which encodes the $\mathrm{E} 167 \mathrm{~K}$ aminoacidic substitution, acts as a measure of hepatic TG content, serum aminotransferases, and lower serum lipoproteins. ${ }^{78,158} \mathrm{~A}$ case-control study on the Han Chinese population indicates a mutation 
in TM6SF2 rs58542926 was substantially associated with increased NAFLD risk in the Chinese population, independent of the Patatin-like phospholipase domain-containing 3 gene rs738409 and neurocan gene rs2228603 polymorphisms. ${ }^{160}$ However, it is not clear if this mutation is involved in NAFLD progression and severity. Dongiovanni and colleagues reported that $\mathrm{E} 167 \mathrm{~K}$ carriers showed a protective effect against carotid atherosclerosis. Inhibiting the VLDL secretion from the liver of these carriers induces the protection against CVD, but this protective effect is traded off with the higher risk of severe liver disease. ${ }^{161} \mathrm{~A}$ recent meta-analysis showed that carriers of TM6SF2 rs58542926 T allele were protected against CVD, whereas they have a higher risk for NAFLD; however, this association could not adequately explain the link between NAFLD and CVD. ${ }^{162}$

Microsomal Triglyceride Transfer Protein Gene (MTP/MTTP)

Microsomal transfer protein (MTP) is a lipid transfer protein localized in the endoplasmic reticulum of hepatocytes and enterocytes and play pivotal roles in the development of NAFLD. Many existing studies have shown that a common polymorphism $(-493 \mathrm{G}>\mathrm{T}$, rs1800591 $\mathrm{G}>\mathrm{T})$ in the MTP gene may be implicated in the development and progression of NAFLD. The functional polymorphisms of MTP/MTTP play a crucial role in regulating lipid metabolism, and several studies have investigated these genes. A recent meta-analysis showed that MTP-493G > T (rs1800591) polymorphisms would contribute to the susceptibility to CVD in patients with NAFLD, while MTP rs1800591 polymorphism might be a valuable and practical biomarker for early detection of NAFLD. ${ }^{46}$ In the Japanese population, a study demonstrated that -493 G-allele frequency was significantly higher in patients with biopsy-proven $\mathrm{NASH}$ than in the healthy control group, and the GG genotype in patients with NASH predicted more severe steatosis. ${ }^{163}$ Nevertheless, the results regarding this matter are inconsistent. A study in a Brazilian population showed that there was no significant association between rs1800591 polymorphism and NAFLD. ${ }^{164}$ Peng and co-workers showed that
MTP rs1800804 (-164 T/C) was associated with an increased risk of NAFLD and the level of TG was significantly lower in controls with rs1800804 (-164 C) risk allele. ${ }^{165}$ The MTP rs 1800804 functional polymorphism and TC levels have an interaction. Thereby, risk allele carriers with low cholesterol levels may be predisposed to an increased risk of developing CVD, which seems to be abolished among risk allele carriers with high cholesterol levels.

\section{Tumor Necrosis Factor-alpha Gene (TNF- $\alpha$ )}

The human TNF- $\alpha$ gene is located on chromosome 6p21.3 and transcripts a protein, which functions as a robust biomarker of systemic inflammation and in turn, contributes to IR mechanism through different direct endocrine and indirect modulatory effects of genes involved in glucose and lipid metabolism. ${ }^{166}$ In response to an injury, this gene triggers an inflammatory response that adjusts the IR process in the liver through insulin signal transduction pathways. ${ }^{167}$ Former studies have shown the association between TNF- $\alpha$ polymorphisms and the risk of NAFLD, particularly in Chinese origin populations. G/A variant at the TNF- $\alpha-238$ has been reportedly increased susceptibility to NAFLD. ${ }^{32}$ Evidence shows that TNF- $\alpha$ G to A polymorphism at position -238 is significantly associated with $\mathrm{CAD}$ and that the $-238 \mathrm{~A}$ allele is associated with the increased risk of CAD among the Korean population, indicating that this allele can be utilized as a predictor for CAD in Koreans. ${ }^{168}$ However, it should be considered that these associations might be different in different ethnicities, and different phenotypic, epigenetic, and environmental factors might have different outcomes .${ }^{169-172}$ The variant at TNF- $\alpha-308$ is not associated with NAFLD genesis and development. ${ }^{32}$ However, the TNF- $\alpha-308 \mathrm{G}>\mathrm{A}$ polymorphism is significantly associated with CAD in the Pakistani population. ${ }^{173}$ Similarly, studies conducted on Chinese populations have demonstrated an association between TNF- $\alpha$ -238 polymorphism and the development of CAD in patients with NAFLD. They proposed that TNF- $\alpha$ -238 GA genotype is associated with an increased risk of CAD in patients with NAFLD. TNF- $\alpha-308$ GA heterozygote genotype has been reportedly associated 
with increased levels of TG in patients with NAFLD and CAD. In conclusion, the TNF- $\alpha-308$ GA genotype plays a pivotal role in the trigger and development of CAD in patients with NAFLD. ${ }^{57}$

Manganese Superoxide Dismutase Gene (MnSOD/SOD2)

Manganese superoxide dismutase (MnSOD) is an important antioxidant enzyme. Several studies in animal models have shown that low MnSOD in NAFLD is associated with increased levels of oxidative stress. Several studies have reported that patients with NAFLD have higher levels of MnSOD enzyme. $^{76,174,175}$ Other studies have demonstrated that the mutant genotypes of TC $+\mathrm{CC}$ of C47T (rs4880) polymorphism in SOD2 had a significant impact on the reduction of CAD risk. ${ }^{176}$ Some studies have shown that the levels of systemic MnSOD protein are significantly higher in patients with NASH in comparison with steatotic patients and healthy controls. ${ }^{177}$ Moreover, different studies have shown that allele evidence that carriage of rs4880 polymorphism involved in determining the susceptibility to fibrogenesis and oxidative stress, respectively, have been associated with the severity of liver fibrosis in adults and children with NAFLD. ${ }^{177}$

Membrane-bound O-acyltransferase Domaincontaining 7 (MBBOAT7)

Membrane-bound O-acyltransferase domain-containing 7 (MBOAT7) has been recently proposed as a gene involved in NAFLD pathogenesis that encodes a membrane-bound enzyme, which integrates arachidonic acid and other unsaturated fatty acids into phosphatidylinositol and other phospholipids under a remodeling Lands cycle. Explicitly, the common rs641738 $\mathrm{C}>\mathrm{T}$ variant has been associated with variation at the 3' untranslated region of MBOAT7, which is a marker of MBOAT downregulation at the mRNA and protein levels. Carriers of this variant showed reduced levels of phosphatidyl-inositol containing arachidonic acid in hepatocytes and in the bloodstream. ${ }^{178,179}$ The MBOAT7 rs641738 variant has been reportedly a biomarker of NAFLD risk, inflammation, and fibrosis, ${ }^{178}$ as well as an increased risk of alcoholic cirrhosis.
Furthermore, this MBOAT7 rs641738 polymorphism has been associated with NAFLD progression to HCC. ${ }^{180}$ The other recently identified genetic factor of NAFLD is a variation at the Glucokinase regulator (GCKR) gene locus. ${ }^{181,182,183,184}$ GCKR modulates the inflow of glucose in hepatocytes and functions as the regulator of lipogenesis. A common mutation (rs1260326), encoding for the P446L protein, has been reported to represent the causal variant associated with the hepatic phenotype. ${ }^{185,186,186,187}$ Under a negative feedback loop, the GCKR regulates the fructose-6-phosphate pathway through inhibiting glucokinase. ${ }^{188}$ The occurrence of the missense variant impairs the protein activity through which the GCKR does not inhibit glucokinase in response to high levels of fructose-6-phosphate, resulting in triggering the hepatic glucose uptake and glycolysis and then acetyl-CoA synthesis that is a ratelimiting substrate for lipogenesis. This process reduces circulating glucose and thus increases insulin sensitivity while enhancing the production of malonyl-CoA, which augments hepatic fat buildup through inhibiting fatty acid translocation to the mitochondria and beta-oxidation. On the contrary, recent data revealed that the rs 4841132 variant of protein phosphatase 1 regulatory subunit 3B (PPP1R3B) could serve as a protective agent against hepatic fat accumulation in the subjects at the risk of NAFLD through lipogenesis reduction. The PPP1R3B helps the synthesis of glycogen in response to excessive energy supply, likely protecting against hepatic fat accumulation in at-risk individuals through the reduction of lipogenesis. ${ }^{189}$ This common variant has been associated with reduced risk of liver disease progression in individuals at high risk of NASH. ${ }^{54}$ However, the overall impact of PPP1R3B variant on the risk of liver-related clinical events is still controversial. ${ }^{190}$ Other SNPs have been associated with NAFLD, ${ }^{74,77,80,191}$ and whilst biologically plausible, their association still warrants further validation, ${ }^{77}$ and the link with CVD is mostly unknown.

\section{CONCLUSION}

NAFLD is often associated with IR and is 
strongly associated with T2DM and obesity. Patients with NAFLD also have a higher risk of developing CVDs, including coronary heart disease and stroke. NAFLD confers increased CVD risk independent of traditional cardiovascular risk factors and MetS. NAFLD and CVD have been a significant public health problem worldwide. These two diseases are considered as the consequence of a complex interplay between genetics, diet, and environment. Recent evidence on the association of the genetic polymorphisms between NAFLD and CVD may provide a new perspective on the prevention, diagnosis, and treatment of these diseases. A novel strategy used by researchers is to characterize the shared genetic basis of NAFLD and CVD. Findings on the shared genetic risks and their biological overlap could significantly contribute to the development of precise medical theranostics (Theranostics is a new field of medicine which combines specific targeted therapy based on specific targeted diagnostic tests. With a key focus on patient centered care, theranostics provides a transition from conventional medicine to a contemporary personalized and precision medicine approach.) through effective patient stratification and identification of preventive and therapeutic strategies. The role of genetic screening for NAFLD and CVD prevention is in initial stages, and further studies are needed to reveal underlying mechanisms and the causal relationship between the two disorders.

The current evidence demonstrates a strong link between NAFLD and increased risk of CVDs in individuals with or without coexisting MetS. NAFLD is a risk factor of poor cardiovascular outcomes independent of other traditional risk factors of CVD, including MetS and hypertension. Despite evidence linking increased CVD risk with NAFLD, there is still uncertainty regarding the prognostic role of NAFLD in risk stratification for CVD. Developing genetic-based diagnosis and management would highlight the development of more individualized treatment and precision medicine for effective management of these disorders. There are some essential questions to be answered in this regard. First, whether adding NAFLD as an independent risk factor to the traditionally available risk scoring systems would enhance the risk predicting of CVDs. Second, whether the prognostic value of NAFLD in the development and progression of CVDs only applies to NASH or it is also associated with simple steatosis is still unclear. Third, whether genetic traits in NAFLD carry the same cardiovascular risk as MetS-associated NAFLD. Finally, further follow-up studies are necessary to identify the pathophysiology linking NAFLD with a CVD risk score.

\section{ETHICAL APPROVAL}

There is nothing to be declared.

\section{CONFLICT OF INTEREST}

The authors declare no conflict of interest related to this work.

\section{ACKNOWLEDGMENTS}

This review is the result of a medical thesis numbered 9313101006, registered at the Ethics Committee of Tehran University of Medical Sciences (number: IR.TUMS.VCR.REC.1396.4665). The study was sponsored by the University Research Deputy, Digestive Disease Research Institute, Shariati Hospital, and Hoveizeh Cohort Study in AJUMS.

\section{REFERENCES}

1. Adams LA, Lymp JF, St. Sauver J, Sanderson SO, Lindor KD, Feldstein A, et al. The natural history of nonalcoholic fatty liver disease: A population-based cohort study. Gastroenterology 2005;129:113-21. doi: 10.1053/j.gastro.2005.04.014.

2. Wong VW, Wong GL, Yeung JC, Fung CY, Chan JK, Chang $\mathrm{ZH}$, et al. Long-term clinical outcomes after fatty liver screening in patients undergoing coronary angiogram: A prospective cohort study. Hepatology 2016;63:754-63. doi: 10.1002/hep.28253.

3. 3. Treeprasertsuk S, Björnsson E, Enders F, Suwanwalaikorn S, Lindor KD. NAFLD fibrosis score: A prognostic predictor for mortality and liver complications among NAFLD patients. World J Gastroenterol 2013;19:1219-29. doi: 10.3748/wjg.v19.i8.1219.

4. Angulo P. Medical progress: Nonalcoholic fatty liver disease. New Engl J Med 2002; 1221-31.

5. Ekstedt M, Franzén LE, Mathiesen UL, Thorelius L, Holmqvist M, Bodemar G, et al. Long-term follow-up of patients with NAFLD and elevated liver enzymes. Hepatology 2006;44:865-73. doi: 10.1002/hep.21327.

6. Matteoni CA, Younossi ZM, Gramlich T, Boparai N, Liu YC, McCullough AJ. Nonalcoholic fatty liver disease: A spectrum of clinical and pathological severity. Gastroenterology 
1999;116:1413-9. doi: 10.1016/s0016-5085(99)70506-8.

7. Targher G, Day CP, Bonora E. Risk of cardiovascular disease in patients with nonalcoholic fatty liver disease. $N$ Engl J Med 2010;363:1341-50. doi: 10.1056/NEJMra0912063.

8. James SL, Abate D, Abate KH, Abay SM, Abbafati C, Abbasi N, et al. Global, regional, and national incidence, prevalence, and years lived with disability for 354 diseases and injuries for 195 countries and territories, 1990-2017: a systematic analysis for the Global Burden of Disease Study 2017. Lancet 2018;392:1789-1858. doi: 10.1016/S01406736(18)32279-7.

9. Yalamanchili K, Saadeh S, Klintmalm GB, Jennings LW, Davis GL, Wakai T, et al. Outcomes of curative treatment for hepatocellular cancer in nonalcoholic steatohepatitis versus hepatitis $\mathrm{C}$ and alcoholic liver disease. Hepatology 2016;35:e0186715.

10. Roth GA, Abate D, Abate KH, Abay SM, Abbafati C, Abbasi N, et al. Global, regional, and national age-sex-specific mortality for 282 causes of death in 195 countries and territories, 1980-2017: a systematic analysis for the Global Burden of Disease Study 2017. Lancet 2018;392:1736-88. doi: 10.1016/S0140-6736(18)32203-7.

11. Assy N, Djibre A, Farah R, Grosovski M, Marmor A. Presence of coronary plaques in patients with nonalcoholic fatty liver disease. Radiology 2010;254:393-400. doi: 10.1148/ radiol.09090769.

12. Nalini M, Oranuba E, Poustchi H, Sepanlou SG, Pourshams A, Khoshnia M, et al. Causes of premature death and their associated risk factors in the Golestan Cohort Study, Iran. BMJ Open 2018;8:e021479. doi: 10.1136/bmjopen-2018-021479.

13. Alexander M, Loomis AK, van der Lei J, Duarte-Salles T, Prieto-Alhambra D, Ansell D, et al. Non-alcoholic fatty liver disease and risk of incident acute myocardial infarction and stroke: findings from matched cohort study of 18 million European adults. BMJ 2019;367:15367. doi: 10.1136/bmj.15367.

14. Kotronen A, Yki-Järvinen H. Fatty liver: A novel component of the metabolic syndrome. Arterioscler Thromb Vasc Biol 2008;28:27-38. doi: 10.1161/ATVBAHA.107.147538.

15. Dunn W, Xu R, Wingard DL, Rogers C, Angulo P, Younossi $\mathrm{ZM}$, et al. Suspected nonalcoholic fatty liver disease and mortality risk in a population-based cohort study. $A m J$ Gastroenterol 2008;103:2263-71. doi: 10.1111/j.15720241.2008.02034.x.

16. Ruttmann E, Brant LJ, Concin H, Diem G, Rapp K, Ulmer H. $\gamma$-glutamyltransferase as a risk factor for cardiovascular disease mortality: An epidemiological investigation in a cohort of 163944 Austrian adults. Circulation 2005;112:2130-7. doi:10.1161/CIRCULATIONAHA.105.552547.

17. Wannamethee G, Ebrahim S, Shaper AG. Gamma-glutamyltransferase: Determinants and association with mortality from ischemic heart disease and all causes. Am J Epidemiol 1995;142:699-708. doi: 10.1093/oxfordjournals.aje.a117699.

18. Fraser A, Harris R, Sattar N, Ebrahim S, Smith GD, Lawlor DA.
Gamma-glutamyltransferase is associated with incident vascular events independently of alcohol intake: Analysis of the British Women's Heart and Health study and metaanalysis. Arterioscler Thromb Vasc Biol 2007;27:2729-35. doi: 10.1161/ATVBAHA.107.152298.

19. Arulanandan A, Ang B, Bettencourt R, Hooker J, Behling C, Lin GY, et al. Association Between Quantity of Liver Fat and Cardiovascular Risk in Patients With Nonalcoholic Fatty Liver Disease Independent of Nonalcoholic Steatohepatitis. Clin Gastroenterol Hepatol 2015;13:1513-20.e1. doi: 10.1016/j.cgh.2015.01.027.

20. Hamaguchi M, Kojima T, Takeda N, Nagata C, Takeda J, Sarui $\mathrm{H}$, et al. Nonalcolholic fatty liver disease is a novel predictor cardiovascular disease. World J Gastroenterol 2007;13:1579-84. doi: 10.3748/wjg.v13.i10.1579.

21. Haring R, Wallaschofski H, Nauck M, Dörr M, Baumeister SE, Völzke H. Ultrasonographic hepatic steatosis increases prediction of mortality risk from elevated serum gammaglutamyl transpeptidase levels. Hepatology 2009;50:140311. doi: 10.1002/hep.23135.

22. Soderberg C, Stål P, Askling J, Glaumann H, Lindberg G, Marmur J, et al. Decreased survival of subjects with elevated liver function tests during a 28 -year follow-up. Hepatology 2010;51:595-602. doi: 10.1002/hep.23314.

23. Ekstedt M, Hagström H, Nasr P, Fredrikson M, Stål P, Kechagias $\mathrm{S}$, et al. Fibrosis stage is the strongest predictor for disease-specific mortality in NAFLD after up to 33 years of follow-up. Hepatology 2015;61:1547-54. doi: 10.1002/ hep. 27368 .

24. Pickhardt PJ, Hahn L, Muñoz del Rio A, Park SH, Reeder SB, Said A. Natural history of hepatic steatosis: Observed outcomes for subsequent liver and cardiovascular complications. AJR Am J Roentgenol 2014;202:752-8. doi: 10.2214/AJR.13.11367.

25. Zeb I, Li D, Budoff MJ, Katz R, Lloyd-Jones D, Agatston $\mathrm{A}$, et al. Nonalcoholic Fatty Liver Disease and Incident Cardiac Events the Multi-Ethnic Study of Atherosclerosis. J Am Coll Cardiol 2016;67:1965-6. doi: 10.1016/j. jacc.2016.01.070.

26. Kim D, Kim WR, Kim HJ, Therneau TM. Association between noninvasive fibrosis markers and mortality among adults with nonalcoholic fatty liver disease in the United States. Hepatology 2013;57:1357-65. doi: 10.1002/hep.26156.

27. Emre A, Terzi S, Celiker E, Sahin S, Yazici S, Erdem A, et al. Impact of Nonalcoholic Fatty Liver Disease on Myocardial Perfusion in Nondiabetic Patients Undergoing Primary Percutaneous Coronary Intervention for STSegment Elevation Myocardial Infarction. Am J Cardiol 2015;116:1810-4. doi: 10.1016/j.amjcard.2015.09.021.

28. Alberti KG, Eckel RH, Grundy SM, Zimmet PZ, Cleeman JI, Donato KA, et al. Harmonizing the metabolic syndrome: A joint interim statement of the international diabetes federation task force on epidemiology and prevention; National heart, lung, and blood institute; American heart association; World heart federation; International atherosclerosis society; And international association for the study of obesity. Circulation 2009;120:1640-5. doi: 10.1161/CIRCULA- 
TIONAHA.109.192644.

29. Ampuero J, Gallego-Durán R, Romero-Gómez M. Association of NAFLD with subclinical atherosclerosis and coronary-artery disease: meta-analysis. Rev Esp Enferm Dig 2015;107:10-6.

30. Keramati AR, Fathzadeh M, Go GW, Singh R, Choi M, Faramarzi S, et al. (2014) A form of the metabolic syndrome associated with mutations in DYRK1B. $N$ Engl J Med 2014;370:1909-19. doi: 10.1056/NEJMoa1301824.

31. Musso G, Bo S, Cassader M, De Michieli F, Gambino R. Impact of sterol regulatory element-binding factor- $1 \mathrm{c}$ polymorphism on incidence of nonalcoholic fatty liver disease and on the severity of liver disease and of glucose and lipid dysmetabolism. Am J Clin Nutr 2013;98:895-906. doi: 10.3945/ajen.113.0

32. Zhou YJ, Li YY, Nie YQ, Yang H, Zhan Q, Huang J, et al. Influence of polygenetic polymorphisms on the susceptibility to non-alcoholic fatty liver disease of Chinese people. J Gastroenterol Hepatol 2010;25:772-7. doi: 10.1111/j.1440-1746.2009.06144.x.

33. Charlton MR, Burns JM, Pedersen RA, Watt KD, Heimbach JK, Dierkhising RA. Frequency and outcomes of liver transplantation for nonalcoholic steatohepatitis in the United States. Gastroenterology 2011;141:1249-53. doi: 10.1053/j.gastro.2011.06.061.

34. Wu S, Wu F, Ding Y, Hou J, Bi J, Zhang Z. Association of non-alcoholic fatty liver disease with major adverse cardiovascular events: A systematic review and meta-analysis. Sci Rep 2016;6:33386. doi: 10.1038/srep33386.

35. Adams LA, Harmsen S, St. Sauver JL, Charatcharoenwitthaya P, Enders FB, Therneau T, et al. Nonalcoholic fatty liver disease increases risk of death among patients with diabetes: A community-based cohort study. Am J Gastroenterol 2010;105:1567-73. doi: 10.1038/ajg.2010.18.

36. Qasim A, Mehta NN, Tadesse MG, Wolfe ML, Rhodes T, Girman C, et al. Adipokines, Insulin Resistance, and Coronary Artery Calcification. J Am Coll Cardiol 2008;52:2316. doi: 10.1016/j.jacc.2008.04.016.

37. Akabame S, Hamaguchi M, Tomiyasu KI, Tanaka M, Yoshiko KT, Nakano K, et al. Evaluation of vulnerable coronary plaques and non-alcoholic fatty liver disease (NAFLD) by 64-detector multislice computed tomography (MSCT). Circ J 2008;72:618-25. doi: 10.1253/circj.72.618.

38. Sinn DH, Cho SJ, Gu S, Seong D, Kang D, Kim H, et al. Persistent Nonalcoholic Fatty Liver Disease Increases Risk for Carotid Atherosclerosis. Gastroenterology 2016;151:4818.e1. doi: 10.1053/j.gastro.2016.06.001.

39. Pais R, Giral P, Khan JF, Rosenbaum D, Housset C, Poynard T, et al. Fatty liver is an independent predictor of early carotid atherosclerosis. J Hepatol 2016;65:95-102. doi: 10.1016/j.jhep.2016.02.023.

40. Park HE, Kwak MS, Kim D, Kim MK, Cha MJ, Choi SY. Nonalcoholic fatty liver disease is associated with coronary artery calcification development: A longitudinal study. $J$ Clin Endocrinol Metab 2016;101:3134-43. doi: 10.1210/ jc.2016-1525.
41. Kim D, Choi SY, Park EH, Lee W, Kang JH, Kim W, et al. Nonalcoholic fatty liver disease is associated with coronary artery calcification. Hepatology 2012;56:605-13. doi: 10.1002/hep.25593.

42. Fracanzani AL, Tiraboschi S, Pisano G, Consonni D, Baragetti A, Bertelli C, et al. Progression of carotid vascular damage and cardiovascular events in non-alcoholic fatty liver disease patients compared to the general population during 10 years of follow-up. Atherosclerosis 2016;246:208-13. doi: 10.1016/j.atherosclerosis.2016.01.016.

43. Nahandi MZ, Khoshbaten M, Ramazanzadeh E, Abbaszadeh L, Javadrashid R, Shirazi KM, et al. Effect of nonalcoholic fatty liver disease on carotid artery intimamedia thickness as a risk factor for atherosclerosis. Gastroenterol Hepatol Bed Bench 2014;7:55-62.

44. Lazo M, Hernaez R, Bonekamp S, Kamel IR, Brancati FL, Guallar E, et al. Non-alcoholic fatty liver disease and mortality among US adults: Prospective cohort study. $B M J$ 2011;343:1245. doi: 10.1136/bmj.d6891.

45. Stepanova M, Younossi ZM. Independent Association Between Nonalcoholic Fatty Liver Disease and Cardiovascular Disease in the US Population. Clin Gastroenterol Hepatol 2012;10:646-50. doi: 10.1016/j.cgh.2011.12.039.

46. Li XL, Sui JQ, Lu LL, Zhang NN, Xu X, Dong QY, et al. Gene polymorphisms associated with non-alcoholic fatty liver disease and coronary artery disease: a concise review. Lipids Health Dis 2016;15:53. doi: 10.1186/s12944-0160221-8.

47. Díez JJ, Iglesias P. The role of the novel adipocyte-derived hormone adiponectin in human disease. Eur J Endocrinol 2003;148:293-300. doi: 10.1530/eje.0.1480293.

48. Li XL, Sui JQ, Lu LL, Zhang NN, Xu X, Dong QY, et al. Gene polymorphisms associated with non-alcoholic fatty liver disease and coronary artery disease: A concise review. Lipids Health Dis 2016;15:53. doi: 10.1186/s12944-0160221-8.

49. Marchesini G, Moscatiello S, Di Domizio S, Forlani G. Obesity-associated liver disease. J Clin Endocrinol Metab 2008;93(11 Suppl 1):S74-80. doi: 10.1210/jc.2008-1399.

50. Ismaiel A, Dumitraşcu DL. Cardiovascular Risk in Fatty Liver Disease: The Liver-Heart Axis-Literature Review. Front Med (Lausanne) 2019;6:202. doi: 10.3389/ fmed.2019.00202.

51. Gupta AC, Misra R, Sakhuja P, Singh Y, Basir SF, Sarin SK. Association of adiponectin gene functional polymorphisms $(-11377 \mathrm{C} / \mathrm{G}$ and $+45 \mathrm{~T} / \mathrm{G})$ with nonalcoholic fatty liver disease. Gene 2012;496:63-7. doi: 10.1016/j. gene.2011.12.023.

52. Kawaguchi T, Shima T, Mizuno M, Mitsumoto Y, Umemura A, Kanbara Y, et al. Risk estimation model for nonalcoholic fatty liver disease in the Japanese using multiple genetic markers. PLoS One 2018;13:e0185490. doi: 10.1371/ journal.pone.0185490.

53. Gregor MF, Hotamisligil GS. Inflammatory Mechanisms in Obesity. Annu Rev Immunol 2011;29:415-45. doi: 10.1146/annurev-immunol-031210-101322. 
54. Liu YL, Reeves HL, Burt AD, Tiniakos D, McPherson S, Leathart JB, et al. TM6SF2 rs58542926 influences hepatic fibrosis progression in patients with non-alcoholic fatty liver disease. Nat Commun 2014;5:4309. doi: 10.1038/ ncomms5309.

55. 55. Anstee QM, Day CP. The Genetics of Nonalcoholic Fatty Liver Disease: Spotlight on PNPLA3 and TM6SF2. Semin Liver Dis 2015;35:270-90. doi: 10.1055/s-00351562947.

56. Kahali B, Liu YL, Daly AK, Day CP, Anstee QM, Speliotes EK. TM6SF2: Catch-22 in the fight against nonalcoholic fatty liver disease and cardiovascular disease? Gastroenterology 2015;148:679-84. doi: 10.1053/j.gastro.2015.01.038.

57. Cheng Y, An B, Jiang M, Xin Y, Xuan S. Association of tumor necrosis factor-alpha polymorphisms and risk of coronary artery disease in patients with non-alcoholic fatty liver disease. Hepat Mon 2015;15:e26818. doi: 10.5812/ hepatmon.26818.

58. Francque S, Laleman W, Verbeke L, Van Steenkiste C, Casteleyn C, Kwanten W, et al. Increased intrahepatic resistance in severe steatosis: Endothelial dysfunction, vasoconstrictor overproduction and altered microvascular architecture. Lab Invest 2012;92:1428-39. doi: 10.1038/ labinvest.2012.103.

59. Targher G, Byrne CD, Lonardo A, Zoppini G, Barbui C. Non-alcoholic fatty liver disease and risk of incident cardiovascular disease: A meta-analysis. J Hepatol 2016;65:589600. doi:10.1016/j.jhep.2016.05.013.

60. Francque SM, van der Graaff D, Kwanten WJ. Non-alcoholic fatty liver disease and cardiovascular risk: Pathophysiological mechanisms and implications. J Hepatol 2016;65:425-43. doi: 10.1016/j.jhep.2016.04.005.

61. Cakir E, Ozbek M, Colak N, Cakal E, Delibaşi T. Is NAFLD an independent risk factor for increased IMT in T2DM? Minerva Endocrinol 2012;37:187-93.

62. Bhatia LS, Curzen NP, Byrne CD. Nonalcoholic fatty liver disease and vascular risk. Curr Opin Cardiol 2012;27:4208. doi: 10.1097/HCO.0b013e328354829c.

63. Bhatia LS, Curzen NP, Calder PC, Byrne CD. Non-alcoholic fatty liver disease: A new and important cardiovascular risk factor? Eur Heart J 2012;33:1190-200. doi: 10.1093/ eurheartj/ehr453.

64. Fabbrini E, Magkos F, Mohammed BS, Pietka T, Abum$\operatorname{rad}$ NA, Patterson BW, et al. Intrahepatic fat, not visceral fat, is linked with metabolic complications of obesity. Proc Natl Acad Sci U S A 2009;106:15430-5. doi: 10.1073/ pnas.0904944106.

65. Al-Serri A, Anstee QM, Valenti L, Nobili V, Leathart JB, Dongiovanni $\mathrm{P}$, et al. The SOD2 C47T polymorphism influences NAFLD fibrosis severity: Evidence from casecontrol and intra-familial allele association studies. $J$ Hepatol 2012;56:448-54. doi: 10.1016/j.jhep.2011.05.029.

66. Alexander M, Loomis AK, Van Der Lei J, Duarte-Salles T, Prieto-Alhambra D, Ansell D, et al. Non-alcoholic fatty liver disease and risk of incident acute myocardial infarction and stroke: Findings from matched cohort study of 18 million European adults. BMJ 2019;367:15367. doi: 10.1136/bmj. 15367.

67. Musso G, Gambino R, Tabibian JH, Ekstedt M, Kechagias S, Hamaguchi M, et al. Association of Non-alcoholic Fatty Liver Disease with Chronic Kidney Disease: A Systematic Review and Meta-analysis. PLoS Med 2014;11:e1001680. doi: 10.1371/journal.pmed.1001680.

68. Carter A, Brackley SM, Gao J, Mann JP. The global prevalence and genetic spectrum of lysosomal acid lipase deficiency: A rare condition that mimics NAFLD. J Hepatol 2019;70:142-50. doi: 10.1016/j.jhep.2018.09.028.

69. Third Report of the National Cholesterol Education Program (NCEP) Expert Panel on Detection, Evaluation, and Treatment of High Blood Cholesterol in Adults (Adult Treatment Panel III) final report. Circulation 2002;106:3143-421.

70. Lazarus JV., Ekstedt M, Marchesini G, Mullen J, Novak K, Pericàs JM, et al. A cross-sectional study of the public health response to non-alcoholic fatty liver disease in Europe. $J$ Hepatol 2020;72:14-24. doi: 10.1016/j.jhep.2019.08.027.

71. Singh R, De Aguiar RB, Naik S, Mani S, Ostadsharif K, Wencker D, et al. LRP6 enhances glucose metabolism by promoting TCF7L2-dependent insulin receptor expression and IGF receptor stabilization in humans. Cell Metab 2013;17:197-209. doi: 10.1016/j.cmet.2013.01.009.

72. Roshandel G, Khoshnia M, Poustchi H, Hemming K, Kamangar F, Gharavi A, et al. Effectiveness of polypill for primary and secondary prevention of cardiovascular diseases (PolyIran): a pragmatic, cluster-randomised trial. Lancet 2019;394:672-83. doi: 10.1016/S0140-6736(19)31791-X.

73. Tarnoki AD, Tarnoki DL, Bata P, Littvay L, Osztovits J, Jermendy G, et al. Heritability of non-alcoholic fatty liver disease and association with abnormal vascular parameters: A twin study. Liver Int 2012;32:1287-93. doi: 10.1111/j.1478-3231.2012.02823.x.

74. Loomba R, Schork N, Chen CH, Bettencourt R, Bhatt A, Ang B, et al. Heritability of Hepatic Fibrosis and Steatosis Based on a Prospective Twin Study. Gastroenterology 2015;149:1784-93. doi: 10.1053/j.gastro.2015.08.011.

75. Hsieh CJ, Wang PW, Hu TH. Association of adiponectin gene polymorphism with nonalcoholic fatty liver disease in Taiwanese patients with type 2 diabetes. PLoS One 2015;10:e0127521. doi: 10.1371/journal.pone.0127521.

76. Kohjima M, Enjoji M, Higuchi N, Kato M, Kotoh K, Yoshimoto $\mathrm{T}$, et al. Re-evaluation of fatty acid metabolismrelated gene expression in nonalcoh fatty liver disease. Int J Mol Med 2007;20:351-80.

77. Eslam M, George J. Genetic contributions to NAFLD: leveraging shared genetics to uncover systems biology. Nat Rev Gastroenterol Hepatol 2020;17:40-52. doi: 10.1038/ s41575-019-0212-0.

78. Kozlitina J, Smagris E, Stender S, Nordestgaard BG, Zhou HH, Tybjærg-Hansen A, et al. Exome-wide association study identifies a TM6SF2 variant that confers susceptibility to nonalcoholic fatty liver disease. Nat Genet 2014;46:352-6. doi: 10.1038/ng.2901. 
79. Romeo S, Kozlitina J, Xing C, Pertsemlidis A, Cox D, Pennacchio LA, et al. Genetic variation in PNPLA3 confers susceptibility to nonalcoholic fatty liver disease. Nat Genet 2008;40:1461-5. doi: 10.1038/ng.257.

80. Speliotes EK, Yerges-Armstrong LM, Wu J, Hernaez R, Kim LJ, Palmer CD, et al. Genome-wide association analysis identifies variants associated with nonalcoholic fatty liver disease that have distinct effects on metabolic traits. PLoS Genet 2011;7:e1001324. doi: 10.1371/journal. pgen.1001324.

81. Liu YL, Patman GL, Leathart JB, Piguet AC, Burt AD, Dufour JF, et al. Carriage of the PNPLA3 rs738409 C >g polymorphism confers an increased risk of non-alcoholic fatty liver disease associated hepatocellular carcinoma. $J$ Hepatol 2014;61:75-81. doi: 10.1016/j.jhep.2014.02.030.

82. Sookoian S, Pirola CJ. Meta-analysis of the influence of I148M variant of patatin-like phospholipase domain containing 3 gene (PNPLA3) on the susceptibility and histological severity of nonalcoholic fatty liver disease. Hepatology 2011;53:1883-94. doi: 10.1002/hep.24283.

83. Valenti L, Alisi A, Galmozzi E, Bartuli A, Del Menico B, Alterio A, et al. I148M patatin-like phospholipase domaincontaining 3 gene variant and severity of pediatric nonalcoholic fatty liver disease. Hepatology 2010;52:1274-80. doi: 10.1002/hep.23823.

84. Stender S, Kozlitina J, Nordestgaard BG, Tybjærg-Hansen A, Hobbs HH, Cohen JC. Adiposity amplifies the genetic risk of fatty liver disease conferred by multiple loci. Nat Genet 2017;49:842-7. doi: 10.1038/ng.3855.

85. BasuRay S, Smagris E, Cohen JC, Hobbs HH. The PNPLA3 variant associated with fatty liver disease (I148M) accumulates on lipid droplets by evading ubiquitylation. Hepatology 2017;66:1111-24. doi: 10.1002/hep.29273.

86. Horton JD, Bashmakov Y, Shimomura I, Shimano H. Regulation of sterol regulatory element binding proteins in livers of fasted and refed mice. Proc Natl Acad Sci U S A 1998;95:5987-92. doi: 10.1073/pnas.95.11.5987.

87. Bruschi FV, Tardelli M, Claudel T, Trauner M. PNPLA3 expression and its impact on the liver: current perspectives. Hepat Med 2017;9:55-66. doi: 10.2147/HMER.S125718.

88. Zain SM, Mohamed Z, Mahadeva S, Cheah PL, Rampal S, Chin KF, et al. Impact of leptin receptor gene variants on risk of non-alcoholic fatty liver disease and its interaction with adiponutrin gene. J Gastroenterol Hepatol 2013;28:873-9. doi: 10.1111/jgh.12104.

89. Huang Y, He S, Li JZ, Seo YK, Osborne TF, Cohen JC, et al. A feed-forward loop amplifies nutritional regulation of PNPLA3. Proc Natl Acad Sci U S A 2010;107:7892-7. doi: 10.1073/pnas. 1003585107.

90. Dubuquoy C, Robichon C, Lasnier F, Langlois C, Dugail I, Foufelle F, et al. Distinct regulation of adiponutrin/PNPLA3 gene expression by the transcription factors ChREBP and SREBP1c in mouse and human hepatocytes. $J$ Hepatol 2011;55:145-53. doi: 10.1016/j.jhep.2010.10.024.

91. Mitsche MA, Hobbs HH, Cohen JC. Patatin-like phospholipase domain- containing protein 3 promotes transfers of essential fatty acids from triglycerides to phospholipids in hepatic lipid droplets. J Biol Chem 2018;293:6958-68.

92. Donati B, Motta BM, Pingitore P, Meroni M, Pietrelli A, Alisi A, et al. The rs2294918 E434K variant modulates patatinlike phospholipase domain-containing 3 expression and liver damage. Hepatology 2016;63:787-98. doi: 10.1002/ hep. 28370 .

93. Smagris E, Basuray S, Li J, Huang Y, Lai KM V, Gromada $\mathrm{J}$, et al. Pnpla3I148M knockin mice accumulate PNPLA3 on lipid droplets and develop hepatic steatosis. Hepatology 2015;61:108-18. doi: 10.1002/hep.27242.

94. BasuRay S, Wang Y, Smagris E, Cohen JC, Hobbs HH. Accumulation of PNPLA3 on lipid droplets is the basis of associated hepatic steatosis. Proc Natl Acad Sci U S A 2019;116:9521-6. doi: 10.1073/pnas.1901974116.

95. Mondul A, Mancina RM, Merlo A, Dongiovanni P, Rametta R, Montalcini T, et al. PNPLA3 I148M Variant Influences Circulating Retinol in Adults with Nonalcoholic Fatty Liver Disease or Obesity. J Nutr 2015;145:1687-91. doi: 10.3945/jn.115.210633.

96. Bobowski-Gerard M, Paolo Zummo F, Staels B, Lefebvre P, Eeckhoute J. Retinoids Issued from Hepatic Stellate Cell Lipid Droplet Loss as Potential Signaling Molecules Orchestrating a Multicellular Liver Injury Response. Cells 2018;7: 137. doi: 10.3390/cells7090137.

97. Abul-Husn NS, Cheng X, Li AH, Xin Y, Schurmann C, Stevis $\mathrm{P}$, et al. A protein-truncating HSD17B13 variant and protection from chronic liver disease. $N$ Engl J Med 2018;378:1096-106. doi: 10.1056/NEJMoa1712191.

98. Pirola CJ, Garaycoechea M, Flichman D, Arrese M, Martino JS, Gazzi C, et al. Splice variant rs72613567 prevents worst histologic outcomes in patients with nonalcoholic fatty liver disease. J Lipid Res 2019;60:176-85. doi: 10.1194/j1r.P089953.

99. Ma Y, Belyaeva OV, Brown PM, Fujita K, Valles K, Karki S, et al. 17-Beta Hydroxysteroid Dehydrogenase 13 Is a Hepatic Retinol Dehydrogenase Associated With Histological Features of Nonalcoholic Fatty Liver Disease. Hepatology 2019;69:1504-19. doi: 10.1002/hep.30350.

100. Pirazzi C, Valenti L, Motta BM, Pingitore P, Hedfalk K, Mancina RM, et al. PNPLA3 has retinyl-palmitate lipase activity in human hepatic stellate cells. Hum Mol Genet 2014;23:4077-85. doi: 10.1093/hmg/ddu121.

101. Taliento, Dallio, Federico, Prati, Valenti. Novel Insights into the Genetic Landscape of Nonalcoholic Fatty Liver Disease. Int $J$ Environ Res Public Health 2019;16. pii: E2755. doi: 10.3390/ijerph16152755.

102. Cheung CYY, Hui EYL, Cheung BMY, Woo YC, Xu A, Fong $\mathrm{CHY}$, et al. Adiponectin gene variants and the risk of coronary heart disease: A 16-year longitudinal study. Eur J Endocrinol 2014;171:107-15. doi: 10.1530/EJE-14-0079.

103. Chandran M, Phillips SA, Ciaraldi T, Henry RR. Adiponectin: More than just another fat cell hormone? Diabetes Care 2003;26:2442-50. doi: 10.2337/diacare.26.8.2442.

104. Hashemi M, Hanafi Bojd H, Eskandari Nasab E, Bahari A, Hashemzehi NA, Shafieipour S, et al. Association 
of adiponectin rs1501299 and rs266729 gene polymorphisms with nonalcoholic fatty liver disease. Hepat Mon 2013;13:e9527. doi: 10.5812/hepatmon.9527.

105. Gormez S, Demirkan A, Atalar F, Caynak B, Erdim R, Sozer $\mathrm{V}$, et al. Adipose tissue gene expression of adiponectin, tumor necrosis factor- $\alpha$ and leptin in metabolic syndrome patients with coronary artery disease. Intern Med 2011;50:805-10. doi: 10.2169/internalmedicine.50.4753.

106. Foucan L, Ezourhi N, Maimaitiming S, Hedreville S, Inamo J, Atallah A, et al. Adiponectin multimers and ADIPOQ T45G in coronary artery disease in caribbean type 2 diabetic subjects of african descent. Obesity (Silver Spring) 2010;18:1466-8. doi: 10.1038/oby.2009.441.

107. Zhang H, Mo X, Hao Y, Gu D. Association between polymorphisms in the adiponectin gene and cardiovascular disease: A meta-analysis. BMC Med Genet 2012;13:40. doi: 10.1186/1471-2350-13-40.

108. Tureck LV, Leite N, Souza RL, da Silva Timossi L, Osiecki AC, Osiecki R, et al. ADIPOQ single nucleotide polymorphism: Association with adiponectin and lipoproteins levels restricted to men. Meta Gene 2015 ;5:98-104. doi: 10.1016/j.mgene.2015.06.003.

109. Lu H, Sun J, Sun L, Shu X, Xu Y, Xie D. Polymorphism of human leptin receptor gene is associated with type 2 diabetic patients complicated with non-alcoholic fatty liver disease in China. J Gastroenterol Hepatol 2009;24:228-32. doi: 10.1111/j.1440-1746.2008.05544.x.

110. Aller R, De Luis DA, Izaola O, González Sagrado M, Conde R, Pacheco D, et al. Lys656Asn polymorphism of leptin receptor, leptin levels and insulin resistance in patients with non alcoholic fatty liver disease. Eur Rev Med Pharmacol Sci 2012;16:335-41.

111. Takahashi-Yasuno A, Masuzaki H, Miyawaki T, Ogawa Y, Matsuoka N, Hayashi T, et al. Leptin receptor polymorphism is associated with serum lipid levels and impairment of cholesterol lowering effect by simvastatin in Japanese men. Diabetes Res Clin Pract 2003;62:169-75. doi: 10.1016/s0168-8227(03)00163-3.

112. Zhang C, Guo L, Guo X. [Interaction of polymorphisms of Leptin receptor gene Gln223Arg, MnSOD9Ala/Val genes and smoking in nonalcoholic fatty liver disease]. Wei Sheng Yan Jiu 2014;43:724-31.

113. Van Der Vleuten GM, Kluijtmans LA, Hijmans A, Blom HJ, Stalenhoef AFH, De Graaf J. The Gln223Arg polymorphism in the leptin receptor is associated with familial combined hyperlipidemia. Int J Obes 2006;30:892-8. doi: 10.1038/sj.ijo.0803234.

114. Okada T, Ohzeki T, Nakagawa Y, Sugihara S, Arisaka O. Impact of leptin and leptin-receptor gene polymorphisms on serum lipids in Japanese obese children. Acta Paediatr 2010;99:1213-7. doi: 10.1111/j.1651-2227.2010.01778.x.

115. Lakka TA, Rankinen T, Weisnagel SJ, Chagnon YC, Lakka HM, Ukkola O, et al. Leptin and leptin receptor gene polymorphisms and changes in glucose homeostasis in response to regular exercise in nondiabetic individuals: The HERITAGE Family Study. Diabetes 2004;53:1603-8. doi: 10.2337/diabetes.53.6.1603.
116. Kilpeläinen TO, Lakka TA, Laaksonen DE, Mager U, Salopuro $T$, Kubaszek A, et al. Interaction of single nucleotide polymorphisms in ADRB2, ADRB3, TNF, IL6, IGF1R, LIPC, LEPR, and GHRL with physical activity on the risk of type 2 diabetes mellitus and changes in characteristics of the metabolic syndrome: The Finnish Diabetes Prevention Study. Metabolism 2008;57:428-36. doi: 10.1016/j.metabol.2007.10.022.

117. Rosmond R, Chagnon YC, Holm G, Chagnon M, Pérusse L, Lindell K, et al. Hypertension in Obesity and the Leptin Receptor Gene Locus. J Clin Endocrinol Metab 2000;85:3126-31. doi: 10.1210/jcem.85.9.6781.

118. Äijälä M, Santaniemi M, Bloigu R, Kesäniemi YA, Ukkola O. Leptin receptor Arg109 homozygotes display decreased total mortality as well as lower incidence of cardiovascular disease and related death. Gene 2014;534:88-92. doi: 10.1016/j.gene.2013.10.003.

119. Masebe T, Bessong PO, Ndip RN, Meyer D. Genetic variants of APOC3 promoter and HLA-B genes in an HIV infected Cohort in Northern South Africa: A pilot study. Int $J$ Mol Sci 2014;15:11403-15. doi: 10.3390/ijms150711403.

120. Tarr PE, Taffé P, Bleiber G, Furrer H, Rotger M, Martinez R, et al. Modeling the Influence of APOC3, APOE, and TNF Polymorphisms on the Risk of Antiretroviral Therapy-Associated Lipid Disorders . J Infect Dis 2005;191:1419-26. doi: 10.1086/429295.

121. Petersen KF, Dufour S, Hariri A, Nelson-Williams C, Foo $\mathrm{JN}$, Zhang XM, et al. Apolipoprotein $\mathrm{C} 3$ gene variants in nonalcoholic fatty liver disease. $N$ Engl J Med 2010;362:10829. doi: 10.1056/NEJMoa0907295.

122. Dammerman M, Sandkuijl LA, Halaas JL, Chung W, Breslow JL. An apolipoprotein CIII haplotype protective against hypertriglyceridemia is specified by promoter and 3 ' untranslated region polymorphisms. Proc Natl Acad Sci U S A 1993;90:4562-6. doi: 10.1073/pnas.90.10.4562.

123. Guettier JM, Georgopoulos A, Tsai MY, Radha V, Shanthirani S, Deepa R, et al. Polymorphisms in the fatty acidbinding protein 2 and apolipoprotein C-III genes are associated with the metabolic syndrome and dyslipidemia in a South Indian population. J Clin Endocrinol Metab 2005;90:1705-11. doi: 10.1210/jc.2004-1338.

124. Waterworth DM, Talmud PJ, Humphries SE, Wicks PD, Sagnella GA, Strazzullo P, et al. Variable effects of the APOC3-482C $>\mathrm{T}$ variant on insulin, glucose and triglyceride concentrations in different ethnic groups. Diabetologia 2001;44:245-8. doi: 10.1007/s001250051607.

125. Li MR, Zhang SH, Chao K, Liao XH, Yao JY, Chen MH, et al. Apolipoprotein C3 (-455T $>$ C) polymorphism confers susceptibility to nonalcoholic fatty liver disease in the Southern Han Chinese population. World J Gastroenterol 2014;20:14010-7. doi: 10.3748/wjg.v20.i38.14010.

126. Lin B, Huang Y, Zhang M, Wang J, Wu Y. Association between apolipoprotein C3 Sst I, T-455C, C-482T and $\mathrm{C} 1100 \mathrm{~T}$ polymorphisms and risk of coronary heart disease. BMJ Open 2014;4:e004156. doi: 10.1136/bmjopen-2013-004156.

127. Ding Y, Zhu MA, Wang ZX, Zhu J, Feng JB, Li DS. Associ- 
ations of polymorphisms in the apolipoprotein APOA1-C3A5 gene cluster with acute coronary syndrome. $J$ Biomed Biotechnol 2012;2012:509420. doi: 10.1155/2012/509420.

128. Li WW, Dammerman MM, Smith JD, Metzger S, Breslow JL, Leff T. Common genetic variation in the promoter of the human apo CIII gene abolishes regulation by insulin and may contribute to hypertriglyceridemia. J Clin Invest 1995;96:2601-5. doi: 10.1172/JCI118324.

129. Jong MC, Hofker MH, Havekes LM. Role of apoCs in lipoprotein metabolism: Functional differences between ApoC1, ApoC2, and ApoC3. Arterioscler Thromb Vasc Biol 1999;19:472-84. doi: 10.1161/01.atv.19.3.472.

130. Cooper AD. Role of the Liver in the Degradation of Lipoproteins. Gastroenterology 1985;88:192-205. doi: 10.1016/ s0016-5085(85)80155-4.

131. Llauradó G, Sevastianova K, Sädevirta S, Hakkarainen A, Lundbom N, Orho-Melander M, et al. Liver fat content and hepatic insulin sensitivity in overweight patients with type 1 diabetes. J Clin Endocrinol Metab 2015;100:607-16. doi: 10.1210/jc.2014-3050.

132. Niu TH, Jiang M, Xin YN, Jiang XJ, Lin ZH, Xuan SY. Lack of association between apolipoprotein $\mathrm{C} 3$ gene polymorphisms and risk of nonalcoholic fatty liver disease in a Chinese Han population. World $J$ Gastroenterol 2014;20:3655-62. doi: 10.3748/wjg.v20.i13.3655.

133. Cui F, Li K, Li Y, Zhang X, An C. Apolipoprotein C3 genetic polymorphisms are associated with lipids and coronary artery disease in a Chinese population. Lipids Health Dis 2014;13:170. doi: 10.1186/1476-511X-13-170.

134. Thamer C, Haap M, Volk A, Maerker E, Becker R, Bachmann $\mathrm{O}$, et al. Evidence for greater oxidative substrate flexibility in male carriers of the Pro 12 Ala polymorphism in PPARgamma2. Horm Metab Res 2002;34:132-6. doi: 10.1055/s2002-23196.

135. Dimitrova-Shumkovska J, Veenman L, Ristoski T, Leschiner S, Gavish M. Chronic high fat, high cholesterol supplementation decreases $18 \mathrm{kDa}$ Translocator Protein binding capacity in association with increased oxidative stress in rat liver and aorta. Food Chem Toxicol 2010;48:910-21. doi: 10.1016/j.fct.2009.12.032.

136. Lee YH, Bae SC, Song GG. Meta-analysis of associations between the peroxisome proliferator-activated receptor- $\gamma$ Pro12Ala polymorphism and susceptibility to nonalcoholic fatty liver disease, rheumatoid arthritis, and psoriatic arthritis. Genet Test Mol Biomarkers 2014;18:341-8. doi: 10.1089/gtmb.2013.0503.

137. Domenici FA, Brochado MJF, Martinelli A de LC, Zucoloto S, da Cunha SF de C, Vannucchi H. Peroxisome proliferator-activated receptors alpha and gamma2 polymorphisms in nonalcoholic fatty liver disease: A study in Brazilian patients. Gene 2013;529:326-31. doi: 10.1016/j. gene.2013.06.091.

138. Wang J, Guo X, Wu P, Song J, Ye C, Yu S, et al. Association between the Pro12Ala polymorphism of PPAR- $\gamma$ gene and the non-alcoholic fatty liver disease: A meta-analysis. Gene 2013;528:328-34. doi: 10.1016/j.gene.2013.07.014.
139. Danesh J, Collins R, Peto R. Lipoprotein(a) and coronary heart disease: Meta-analysis of prospective studies. Circulation 2000;102:1082-5. doi: 10.1161/01.cir.102.10.1082.

140. Xie HJ, Hai B, Wu M, Chen Q, Liu MM, Dong C, et al. Analysis on the association between PPAR $\alpha / \gamma$ polymorphisms and lipoprotein(a) in a Chinese Han population. Mol Genet Genomics 2014;289:981-7. doi: 10.1007/ s00438-014-0866-9.

141. Qian Y, Li P, Zhang J, Shi Y, Chen K, Yang J, et al. Association between peroxisome proliferator-activated receptor-alpha, delta, and gamma polymorphisms and risk of coronary heart disease: A case-control study and meta-analysis. Medicine (Baltimore) 2016;95:e4299. doi: 10.1097/MD.0000000000004299.

142. Oladi M, Nohtani M, Avan A, Mirhafez SR, Tajbakhsh A, Ghasemi F, et al. Impact of the C1431T polymorphism of the peroxisome proliferator activated receptor-gamma (PPAR- $\gamma$ ) gene on fasted serum lipid levels in patients with coronary artery disease. Ann Nutr Metab 2015;66:149-54. doi: $10.1159 / 000381358$.

143. Wan J, Xiong S, Chao S, Xiao J, Ma Y, Wang J, et al. PPAR $\gamma$ gene C161T substitution alters lipid profile in Chinese patients with coronary artery disease and type 2 diabetes mellitus. Cardiovasc Diabetol 2010;9:13. doi: 10.1186/1475-2840-9-13.

144. Hui Y, Yu-yuan L, Yu-qiang N, Wei-hong S, Yan-lei D, Xiao-bo L, et al. Effect of peroxisome proliferator-activated receptors- $\gamma$ and co-activator- $1 \alpha$ genetic polymorphisms on plasma adiponectin levels and susceptibility of nonalcoholic fatty liver disease in Chinese people. Liver Int 2008;28:385-92. doi: 10.1111/j.1478-3231.2007.01623.x

145. Bauer S, Wanninger J, Schmidhofer S, Weigert J, Neumeier M, Dorn C, et al. Sterol regulatory element-binding protein 2 (SREBP2) activation after excess triglyceride storage induces chemerin in hypertrophic adipocytes. Endocrinology 2011;152:26-35. doi: 10.1210/en.2010-1157.

146. Shimano H. Sterol regulatory element-binding proteins (SREBPs): Transcriptional regulators of lipid synthetic genes. Prog Lipid Res 2001;40:439-52. doi: 10.1016/ s0163-7827(01)00010-8.

147. Vaidya D, Szklo M, Cushman M, Holvoet P, Polak J, Bahrami $\mathrm{H}$, et al. Association of endothelial and oxidative stress with metabolic syndrome and subclinical atherosclerosis: Multi-ethnic study of atherosclerosis. Eur J Clin Nutr 2011;65:818-25. doi: 10.1038/ejen.2011.47.

148. Musso G, Cassader M, Bo S, De Michieli F, Gambino R. Sterol regulatory element-binding factor 2 (SREBF-2) predicts 7-year NAFLD incidence and severity of liver disease and lipoprotein and glucose dysmetabolism. Diabetes 2013;62:1109-20. doi: 10.2337/db12-0858.

149. Hua X, Sakai J, Ho YK, Goldstein JL, Brown MS. Hairpin orientation of sterol regulatory element-binding protein-2 in cell membranes as determined by protease protection. J Biol Chem 1995;270:29422-7. doi: 10.1074/jbc.270.49.29422.

150. Bommer GT, MacDougald OA. Regulation of lipid homeostasis by the bifunctional SREBF2-miR33a locus. Vol. 13, Cell Metabolism. Cell Metab 2011;13:241-7. doi: 
10.1016/j.cmet.2011.02.004.

151. Sato R. Sterol metabolism and SREBP activation. Arch Biochem Biophys 2010;501:177-81. doi: 10.1016/j. abb.2010.06.004.

152. Caballero F, Fernández A, De Lacy AM, Fernández-Checa JC, Caballería J, García-Ruiz C. Enhanced free cholesterol, SREBP-2 and StAR expression in human NASH. $J$ Hepatol 2009;50:789-96. doi: 10.1016/j.jhep.2008.12.016.

153. Horie $T$, Ono K, Horiguchi M, Nishi H, Nakamura $T$, Nagao K, et al. MicroRNA-33 encoded by an intron of sterol regulatory element-binding protein 2 (Srebp2) regulates HDL in vivo. Proc Natl Acad Sci U S A 2010;107:17321-6. doi: 10.1073/pnas.1008499107.

154. Wang Y, Tong J, Chang B, Wang BF, Zhang D, Wang BY. Relationship of SREBP-2 rs2228314 G $>$ C polymorphism with nonalcoholic fatty liver disease in a Han Chinese population. Genet Test Mol Biomarkers 2014;18:653-7. doi: 10.1089/gtmb.2014.0116.

155. Chen Z, Ding Z, Ma G, Liu N, Qian Q. Sterol regulatory element-binding transcription factor (SREBF)-2, SREBF cleavage-activating protein (SCAP), and premature coronary artery disease in a Chinese population. Mol Biol Rep 2011;38:2895-901. doi: 10.1007/s11033-010-9951-2.

156. Bhatt SP, Nigam $P$, Misra A, Guleria R, Luthra K, Vaidya $\mathrm{M}$, et al. SREBP-2 $1784 \mathrm{G} / \mathrm{C}$ genotype is associated with non-alcoholic fatty liver disease in north Indians. Dis Markers 2011;31:371-7. doi: 10.3233/DMA-2011-0852.

157. Miljkovic I, Yerges-Armstrong LM, Kuller LH, Kuipers AL, Wang X, Kammerer CM, et al. Association analysis of 33 lipoprotein candidate genes in multi-generational families of African ancestry. J Lipid Res 2010;51:1823-31. doi: 10.1194/jlr.M003897.

158. Holmen OL, Zhang H, Fan Y, Hovelson DH, Schmidt EM, Zhou W, et al. Systematic evaluation of coding variation identifies a candidate causal variant in TM6SF2 influencing total cholesterol and myocardial infarction risk. Nat Genet 2014;46:345-51. doi: 10.1038/ng.2926.

159. Zhou Y, Llauradó G, Orešič M, Hyötyläinen T, Orho-Melander M, Yki-Järvinen H. Circulating triacylglycerol signatures and insulin sensitivity in NAFLD associated with the E167K variant in TM6SF2. J Hepatol 2015;62:657-63. doi: 10.1016/j.jhep.2014.10.010.

160. Wang X, Liu Z, Peng Z, Liu W. The TM6SF2 rs58542926 $\mathrm{T}$ allele is significantly associated with non-alcoholic fatty liver disease in Chinese. J Hepatol 2015;62:1438-9. doi: 10.1016/j.jhep.2015.01.040.

161. Dongiovanni P, Petta S, Maglio C, Fracanzani AL, Pipitone R, Mozzi E, et al. Transmembrane 6 superfamily member 2 gene variant disentangles nonalcoholic steatohepatitis from cardiovascular disease. Hepatology 2015;61:506-14. doi: 10.1002/hep.27490.

162. Pirola CJ, Sookoian S. The dual and opposite role of the TM6SF2-rs58542926 variant in protecting against cardiovascular disease and conferring risk for nonalcoholic fatty liver: A meta-analysis. Hepatology 2015;62:1742-56. doi: 10.1002/hep.28142.
163. Bernard S, Touzet S, Personne I, Lapras V, Bondon PJ, Berthezène F, et al. Association between microsomal triglyceride transfer protein gene polymorphism and the biological features of liver steatosis in patients with Type II diabetes. Diabetologia 2000;43:995-9. doi: 10.1007/ s001250051481.

164. Oliveira CPMS, Stefano JT, Cavaleiro AM, Zanella Fortes MAH, Vieira SM, Rodrigues Lima VM, et al. Association of polymorphisms of glutamate-cystein ligase and microsomal triglyceride transfer protein genes in non-alcoholic fatty liver disease. J Gastroenterol Hepatol 2010;25:35761. doi: 10.1111/j.1440-1746.2009.06001.

165. Peng XE, Wu YL, Lu QQ, Hu ZJ, Lin X. MTTP polymorphisms and susceptibility to non-alcoholic fatty liver disease in a Han Chinese population. Liver Int 2014;34:11828. doi: 10.1111/liv.12220.

166. Nishimura F, Iwamoto Y, Mineshiba J, Shimizu A, Soga Y, Murayama Y. Periodontal Disease and Diabetes Mellitus: The Role of Tumor Necrosis Factor- $\alpha$ in a 2-Way Relationship. J Periodontol 2003;74:97-102. doi: 10.1902/ jop.2003.74.1.97.

167. Hotamisligil G k. S, Peraldi P, Budavari A, Ellis R, White MF, Spiegelman BM. IRS-1-Mediated Inhibition of Insulin Receptor Tyrosine Kinase Activity in TNF-alpha- and Obesity-Induced Insulin Resistance. Science 1996;2;271:66570. doi: 10.1126/science.271.5249.665.

168. Cho HC, Yu G, Lee MY, Kim HS, Shin DH, Kim YN. TNF- $\alpha$ polymorphisms and coronary artery disease: Association study in the Korean population. Cytokine 2013;62:104-9. doi: 10.1016/j.cyto.2013.02.008.

169. Keso T, Perola M, Laippala P, Ilveskoski E, Kunnas TA, Mikkelsson J, et al. Polymorphisms within the tumor necrosis factor locus and prevalence of coronary artery disease in middle-aged men. Atherosclerosis 2001;154:691-7. doi: 10.1016/s0021-9150(00)00602-x.

170. Herrmann SM, Ricard S, Nicaud V, Mallet C, Arveiler D, Evans A, et al. Polymorphisms of the tumour necrosis factor- $\alpha$ gene, coronary heart disease and obesity. Eur J Clin Invest 1998;28:59-66. doi: 10.1046/j.1365-2362.1998.00244.x

171. Wang XL, Oosterhof J. Tumour necrosis factor alpha G-308-- > A polymorphism and risk for coronary artery disease. Clin Sci (Lond) 2000;98:435-7.

172. Keso T, Perola M, Laippala P, Ilveskoski E, Kunnas TA, Mikkelsson J, et al. Polymorphisms within the tumor necrosis factor locus and prevalence of coronary artery disease in middle-aged men. Atherosclerosis 2001;154:691-7. doi: 10.1016/s0021-9150(00)00602-x

173. Targher G, Day CP, Bonora E. Risk of cardiovascular disease in patients with nonalcoholic fatty liver disease. $N$ Engl $J$ Med 2010;363:1341-50. doi: 10.1056/NEJMra0912063.

174. Perlemuter G, Davit-Spraul A, Cosson C, Conti M, Bigorgne A, Paradis V, et al. Increase in liver antioxidant enzyme activities in non-alcoholic fatty liver disease. Liver Int 2005 ;25:946-53. doi: 10.1111/j.1478-3231.2005.01126.x

175. Tsuchiya H, Ashla AA, Hoshikawa Y, Matsumi Y, Kanki K, Enjoji $\mathrm{M}$, et al. Iron state in association with retinoid me- 
tabolism in non-alcoholic fatty liver disease. Hepatol Res 2010;40:1227-38. doi: 10.1111/j.1872-034X.2010.00719.x.

176. Tian C, Liu T, Fang S, Du X, Jia C. Association of C47T polymorphism in SOD2 gene with coronary artery disease: A case-control study and a meta-analysis. Mol Biol Rep 2012;39:5269-76. doi: 10.1007/s11033-011-1324-y.

177. Takami Y, Uto H, Tamai T, Sato Y, Ishida Y ichi, Morinaga $\mathrm{H}$, et al. Identification of a novel biomarker for oxidative stress induced by hydrogen peroxide in primary human hepatocytes using the 2-nitrobenzenesulfenyl chloride isotope labeling method. Hepatol Res 2010;40:438-45. doi: 10.1111/j.1872-034X.2009.00615.x.

178. Mancina RM, Dongiovanni P, Petta S, Pingitore P, Meroni M, Rametta R, et al. The MBOAT7-TMC4 Variant rs641738 increases risk of nonalcoholic fatty liver disease in individuals of European descent. Gastroenterology 2016;150:12191230.e6. doi: 10.1053/j.gastro.2016.01.032.

179. Luukkonen PK, Zhou Y, Hyötyläinen T, Leivonen M, Arola J, Orho-Melander M, et al. The MBOAT7 variant rs641738 alters hepatic phosphatidylinositols and increases severity of non-alcoholic fatty liver disease in humans. $J$ Hepatol 2016;65:1263-5. doi: 10.1016/j.jhep.2016.07.045.

180. Donati B, Dongiovanni P, Romeo S, Meroni M, McCain M, Miele L, et al. MBOAT7 rs641738 variant and hepatocellular carcinoma in non-cirrhotic individuals. Sci Rep 2017;7;4492. doi: 10.1038/s41598-017-04991-0.

181. Williams CD, Stengel J, Asike MI, Torres DM, Shaw J, Contreras M, et al. Prevalence of nonalcoholic fatty liver disease and nonalcoholic steatohepatitis among a largely middle-aged population utilizing ultrasound and liver biopsy: A prospective study. Gastroenterology 2011;140:12431. doi: 10.1053/j.gastro.2010.09.038.

182. Wong VWS, Chan HLY, Hui AY, Chan KF, Liew CT, Chan FKL, et al. Clinical and histological features of nonalcoholic fatty liver disease in Hong Kong Chinese. Aliment Pharmacol Ther 2004;20:45-49. doi:10.1111/j.13652036.2004.02012.x

183. Altiparmak E, Köklü S, Yalinkilic M, Yüksel O, Cicek B, Kayacetin E, et al. Viral and host causes of fatty liver in chronic hepatitis B. World J Gastroenterol 2005 28;11:3056-9. doi:10.3748/wjg.v11.i20.3056

184. Rozario R, Ramakrishna B. Histopathological study of chronic hepatitis $\mathrm{B}$ and $\mathrm{C}$ : a comparison of two scoring systems. J Hepatol 2003;38:223-9. doi:10.1016/s01688278(02)00357-4

185. Gordon A, McLean CA, Pedersen JS, Bailey MJ, Roberts SK. Hepatic steatosis in chronic hepatitis B and C: Predictors, distribution and effect on fibrosis. $J$ Hepatol 2005;43:38-44. doi: 10.1016/j.jhep.2005.01.031

186. Thomopoulos KC, Arvaniti V, Tsamantas AC, Dimitropoulou D, Gogos CA, Siagris D, et al. Prevalence of liver steatosis in patients with chronic hepatitis B: A study of associated factors and of relationship with fibrosis. Eur J Gastroenterol Hepatol 2006;18:233-7. doi: 10.1097/00042737-200603000-00002

187. Amarapurkar Dn, Hashimoto E, Lesmana La, Sollano
Jd, Chen Pj, Goh KL. How common is non-alcoholic fatty liver disease in the asia-pacific region and are there local differences? J Gastroenterol Hepatol (australia) 2007;22:788-93.

188. Rozario R, Ramakrishna B. Histopathological study of chronic hepatitis $\mathrm{b}$ and $\mathrm{c}$ : a comparison of two scoring systems. J Hepatol 2003;38:223-9. doi: 10.1016/s01688278(02)00357-4

189. Dongiovanni P, Meroni M, Mancina Rm, Baselli G, Rametta R, Pelusi S, et al. Protein phosphatase 1 regulatory subunit $3 \mathrm{~b}$ gene variation protects against hepatic fat accumulation and fibrosis in individuals at high risk of nonalcoholic fatty liver disease. Hepatol Commun 2018;2:666-75. doi:10.1002/hep4.1192

190. Stender S, Smagris E, Lauridsen Bk, Kofoed Kf, Nordestgaard $\mathrm{Bg}$, Tybjærg-hansen A, et al. Relationship between genetic variation at ppp1r3b and levels of liver glycogen and triglyceride. Hepatology 2018;67:2182-95. doi:10.1002/ hep. 29751

191. Naik A, Košir R, Rozman D. Genomic aspects of NAFLD pathogenesis. Genomics 2013;102: 84-95. doi:10.1016/j. ygeno.2013.03.007 